\title{
Digital game adaptations to attract more girls to play
}

\author{
Ana Luiza do Nascimento Guercy ${ }^{1}$, Lucila Ishitani ${ }^{1}$ \\ ${ }^{1}$ Programa de Pós-Graduação em Informática - PUC Minas \\ Belo Horizonte, MG - Brasil \\ \{analuizanascimento95@hotmail.com, lucila@pucminas.br\}
}

\begin{abstract}
Until the early years of the 21st century, games were seen as activities for male teenagers and adults. Gradually, women are gaining representation in the universe of games, but they still encounter difficulties, face judgments, prejudice, and often feel discouraged to play. Games can encourage girls to see technology positively, which can motivate career choice in computing. As the number of female professionals in computing careers is still small, characterizing what girls like or dislike in games can contribute to the increase in that number. Thus, this work aims to propose adaptations for digital games, to attract more girls to play them. To reach this objective, we conducted interviews with girls, to collect information about what they like or dislike in games, and later a triangulation was performed for validation, which used information extracted from a questionnaire. The analysis of the interviews shows that aspects such as game graphics, the possibility of playing in a group, the reality of the game, and freedom to choose avatars and paths the game will follow are characteristics significantly valued by the participants, regardless of whether they already play games or not. Based on the analysis, this work generated suggestions for better matching games for girls contributing to reducing the gap between men and women in computing careers. Some of the main suggestions address the need to pay attention to how the game will work the interaction between players; the need to provide the gamer constant feedback and rating features such as ranking, promoting competition, and the insertion of female avatars within the games that are representative and that have physical variations in the characters, in addition to representing women as champions and not just as support for other players.
\end{abstract}

Keywords. Girl; Woman; Female gamer; Digital Game; Video game; Gender

\section{Introduction}

The popularity of digital games is constantly growing. Online games have made significant progress, in line with advances in mobile and web technologies, and video games are becoming an increasingly popular entertainment among children, young people, and adults. The use of games grew even more due to the Covid-19 pandemic. Games became essential during the period of social isolation, being a possibility of interaction with other 
people, fun, and entertainment [Laato et al. 2020, Martín-Sómer et al. 2021, Schmidt et al. 2021].

In addition, digital games have transposed a playful role. There are positive impacts of the use of games related to physical health, mental health, cognitive functions, and learning [Cai et al. 2021, Dale et al. 2020, Huang et al. 2017, Zelinski and Reyes 2009].

Traditionally, playing digital games is perceived as an activity for male adolescents and adults [Veltri et al. 2014, Woods 2021, Hartmann and Klimmt 2017]. However, video games are gradually becoming a leisure activity for girls too. Little by little women are gaining representation in the gaming world, as is the case in the USA, where women represent more than $40 \%$ of the players of country [Harrison et al. 2016]. Unfortunately, this scenario of a great number of female players is not yet the same globally and the consumption of games is still scarce for the female audience compared to the male audience [Vermeulen et al. 2016, Cardoso 2019, Woods 2021]. Although the popularity of games has increased among women, they may still find it difficult to enter this universe, facing judgments and prejudices, and often feeling discouraged, due to stereotypes that they do not understand the games, or that they are not good at playing them [Olsson 2018].

The games known as casual, usually played on cell phones or tablets, are feminized compared to games known as "hardcore", which can be played on other platforms, such as game consoles [Ribeiro 2019, Woods 2021, Vanderhoef 2013]. Most of the casual games market is made up of women, and these games are somehow created for the female audience [Benedicta 2021, Jenkins and Cassell 2008]. The increase in the number of women playing occurs exactly in casual games, while the consumption of "hardcore" games is still dominated by the male audience, reinforcing the stereotype of computers as toys for boys, and strengthening the stigma that women cannot be identified as hardcore players [Wasserman and Rittenour 2018, Lima et al. 2019].

Gender bias in video games can be related to women who develop negative views about careers in Science, Technology, Engineering, and Mathematics (STEM). A 2011 survey of university students of STEM courses reported that, for men, the number one factor for the initial interest in STEM careers was games (61\%), while only $29 \%$ of women selected the same response [Fordham et al. 2014]. Thus, encouraging girls to play more video games can stimulate them to study subjects related to technology and related areas [Hosein 2018].

The number of female professionals in Computer Science (CS) careers is still small compared to the number of men. Bearing in mind that games can be a primary contact with technology, in addition to a possible impulse to know or follow the area, it becomes necessary to characterize what girls like and dislike in games and to study what can be adapted within the elements of a game and its development to attract more female players [Rogers 2015]. To meet this need, the general objective of this work is to propose adjustments in digital games, to attract more girls to play.

A qualitative research approach was used for the execution of the proposed search. Data collection was carried out through interviews, which were conducted with girls aged

\footnotetext{
iSys: Revista Brasileira de Sistemas de Informação (iSys: Brazilian Journal of Information Systems) http://seer.unirio.br/index.php/isys/
} 
15 to 24 years. Interviews were conducted with 20 girls who play any kind of game, ten of whom are students in the field of computing, and ten are not students of CS courses. To complement the study, interviews were also conducted with ten girls who are not in the habit of playing games. For data analysis, content analysis was applied [Flick 2008].

This work resulted in a set of suggested adaptations for games, based on the identification of characteristics that participants indicated they liked or disliked in games. Some of the main suggestions address the need to pay attention to how the game will work the interaction between players, whether with the use of video, audio, or chats, and the need to provide the gamer constant feedback and rating features such as ranking, promoting competition. Suggestions that work with the image of women within the games are also mentioned, such as the insertion of female avatars within the games that are representative and that have physical variations in the characters, in addition to representing women as champions, and not just as support for other players, having its own story, not linked to other characters. Besides, the results also contribute to the discussion of previous studies regarding aspects girls would like to see in games and the relationship between games and the choice of a career in Computing.

This article is organized as follows: Section 2 presents the works that support this article; Section 3 presents the methods used for the conduction of this study; Section 4 discusses the results and the validation process; Section 5 presents the main conclusions of this article; Section 5.2 presents suggestions for future work.

\section{Background}

It is through the use of digital games that children generally have the first contact and develop a certain comfort when interacting with computers, which, in turn, helps to promote a little knowledge in computers. Games can make players perceive the computer in a friendly way [Dickey 2006].

The subsections that follow discuss the possible relationship between games and the choice of a CS career and also the gender differences in the use of games, exploring these differences concerning aspects indicated by men and women, as valued or not.

\subsection{Relationship between games and careers in computing}

The number of female professionals in CS careers is still small compared to the number of men and has been decreasing over the years. This is a consequence of the low number of women who choose to graduate in CS courses. For example, in Brazil, according to the Higher Education statistics in the field of Computing [SBC 2019], in 2002 the number of female freshmen in Information Systems courses was 5,900, and in 2019 that number dropped to 3,149 . On the other hand, in the same period, the number of male freshmen increased from 18,876 to 18,956. Following this trend, the number of women completing Information Systems courses was 614 in 2002 and 1,249 in 2019, while the number of men increased from 1,363 to 6,771. This scenario of more men than women entering or graduating occurs in all courses in the field of computing. In total, in 2019, the number of graduates from computer science courses was 6,304 women and 38,983 men.

It has not yet been proven whether there is a causal relationship between playing games and pursuing a career in the STEM field, but encouraging girls to play more

\footnotetext{
iSys: Revista Brasileira de Sistemas de Informação (iSys: Brazilian Journal of Information Systems) http://seer.unirio.br/index.php/isys/
} 
video games makes them up to three times more likely to study subjects related to this field [Hosein 2018, Lin et al. 2020, Zhao and Shute 2019]. This stimulus can come from the fact that digital games designed for girls encourage them to see technology (specifically the computer) as a positive tool, and the use of computers to play can promote the interest of girls in computing and technology [Dickey 2006, Lin et al. 2020, Hartmann and Klimmt 2017]. The results presented by Hosein indicate that playing any type of video game can encourage women to study STEM. Those who are regular players and are STEM graduates are also the least likely to give up their gaming habits.

[Martins et al. 2019] also identified that one of the factors that attract women to technology courses is to provide the contact of girls with the area of computing and games. According to the authors, arousing curiosity about the area in girls since childhood, through contact with games and the use of technology, is also a considerably relevant factor.

In turn, [Lantz 2015] sought to analyze the relationship between the experience of playing video games and the recruitment and retention of women in specialization courses in STEM. The study revealed that there was a significant impact on women in the first year of high school with interest and motivation in STEM courses. The implications of the positive impact of video games on STEM interest and motivation inform educational practices for girls and women.

Finally, [Hosein 2018] enlightens that not all girls who play video games tend to study STEM, and not all girls who study STEM play video games; it is necessary to inspire girls who are already players, without alienating those who are not.

\subsection{Related work}

[Veltri et al. 2014] pointed out six main areas where gender differences are significant in the context of games: adoption, motivation, social interaction, self-presentation, skills, and performance. According to the authors, adoption is linked to the beginning of the habit of playing games: men develop an interest in computer games early in their lives, while women start playing later and spend less time playing than men. This may be due to the influence of gender division of labor, such as the division of domestic tasks that is still demarcated by gender prescriptions [Lin 2008, Woods 2021]. Concerning social interaction, several studies report that female players are more sociable: they are more likely to meet people while playing. In addition, women are more cooperative and use more supportive language to encourage their colleagues [Bergstrom 2019, Dele-Ajayi et al. 2018, Fontoura et al. 2019, Schultheiss 2017, Veltri et al. 2014].

In a complementary way to the study of [Veltri et al. 2014], [Harrison et al. 2016] identified that, in general, women prefer games of logic and skills training. While playing, women are more likely to make friends, participate in groups, seek help, and recruit new female players, activities that focus on relationships and socialization.

[Dele-Ajayi et al. 2018, Dickey 2006, Kaufman et al. 2019, Schultheiss 2017] added that girls show a preference for games in which there is little violence or negative feedback, while boys may supposedly be more used to the violence in the context of a game. However, some studies indicate that the interest of some women in non-violent

iSys: Revista Brasileira de Sistemas de Informação (iSys: Brazilian Journal of Information Systems) http://seer.unirio.br/index.php/isys/ 
games should not be generalized, as this reinforces exclusive stereotypes about the interests of the female players [Fontoura et al. 2019, Jenkins 1998].

[Hartmann and Klimmt 2017] presented two studies that investigated why women are less attracted than men to computer games in Germany and reinforced the aversion of women to games that contain extreme violence, and to games that do not have significant social interaction. [Hartmann and Klimmt 2017] added that two other important factors that make women not play or dislike a certain game are the sexual stereotypes present in female characters, or the characters represented as weak, always protected and saved by male characters; and extreme competition.

[Dickey 2006] further stated that girls indicate a certain preference for game design that includes exploration, collaboration, challenge, adventures, and graphic design. The characteristics that young women prefer include a rich narrative, roles that involve positive action, adequate levels of challenges, opportunities to design, or create, engaging characters, communication and collaboration, use of strategies and skills. [Ribeiro 2019] reinforces the preferences of women for games mentioned by [Dickey 2006], and adds that there is a desire for women to move into roles within the game that are not just supportive, but tactical and more competitive.

Complementing the studies presented, to report and exemplify a concrete vision of how to include more girls in the universe of games, [Cunningham 2016] examined initiatives that encourage gender equality in the design of video games and aimed to understand the ideologies present in the development of commercialized games for girls since gender inequality persists in the video games industry. The author mentions that the widespread cyber harassment of several game creators collectively called Gamergate drew attention to the importance of increasing diversity in the video games industry since in a way it highlighted the culture of oppression against women who play and the low female representation as players or game producers [Kurtz 2017]. Design and video games programs for girls have been cited, where each program emphasizes different economic, cultural, and democratic reasons why girls can and should design video games. A common point in these programs is that, in addition to learning the technical skills of design from video games, video games can change the perspectives of girls, offering opportunities to express themselves, challenge stereotyped representations and create social change [Cunningham 2016].

This work differs from the other works presented since it does not only aim to reaffirm the importance of including girls in games but also aims to propose adaptations in digital games, considering that the works presented did not include what should and should not be adjusted in games based on preferences of girls. The works only commented on initiatives and indicated the relationship between games and careers in STEM, in addition to the current scenario of girls within this domain. This work aims to, from the proposed adjustments for games, attract more girls to play, and for this, characteristics already mentioned and validated in the literature were reused, such as aspects valued or not by girls in games, which complemented the present study. Furthermore, new characteristics were identified.

iSys: Revista Brasileira de Sistemas de Informação (iSys: Brazilian Journal of Information Systems) http://seer.unirio.br/index.php/isys/ 


\section{Methods}

The research methodology adopted in this work can be classified as [Flick 2008]: applied, regarding the purpose; exploratory, regarding the objectives; qualitative, regarding the nature of the data; bibliographic and field research, regarding data collection. Figure 1 shows the summary of methodology steps and the following subsections detail the processes of data collection and analysis.

\section{Initial characteristics identification}

- Interview with 20 girls from 15 to 24 years old, who have the habit to play

- Identification of features present in games that attracted or not these girls

Analysis of the interviews with girls who play games

- Analysis of interviews using the content analysis method

\section{Creation of a Gamebook}

- Virtual catalog with 10 games, mentioned in interviews or in the literature

\section{Gamebook presentation}

- Gamebook presentation for 10 girls from 15 to 24 years old, who are not in the habit of playing

- Interview with the girls to identify what they liked or not in the games presented

\section{Analysis of interviews with girls who are not in the habit of playing games}

- Analysis of interviews using the content analysis method

- Characteristics validation

Validation of analyzes

- Cheking the results using a questionaire

Figure 1. Summary of methodology steps

\subsection{Initial Characteristics Identification}

In this activity, we interviewed 20 girls from 15 to 24 years old who have the habit of playing, to identify what in a game is valued or not by them. [Guest et al. 2006] indicate that considering a homogeneous group, six to 12 interviews may be sufficient to achieve the research objective.

The age interval defined from 15 to 24 years includes adolescents and young adults, considering the study by [Papalia et al. 2006], where it is mentioned that the adolescence cycle is lived from 11 to 18 years old, and the cycle young adult is aged between 19 and 40 years. The chosen interval aimed to cover girls who are at different times in their academic life, to generate a better understanding of the role of games in their career choice. 
Participants were recruited from technical courses, high schools, and universities. The strategy used to invite participants was the "snowball" strategy, based on the indication of girls by the research participants themselves. This method starts from the indication by an individual from the population of others who are also part of it. Similar to the way a snowball accumulates snowflakes as it rolls, the number of participants becomes bigger and bigger [Vinuto 2014]. At the end of each interview, a thank you was sent to the interviewee, and also a request to indicate possible participants. Participants were divided into two groups: ten girls were students in the field of computing and ten girls were not students of CS courses. The interviews were semi-structured. The questions can be found in the Appendix A.

\subsection{Analysis of the interviews with girls who play games}

The method chosen for the analysis of the interviews was the content analysis, to verify the characteristics that the participants indicated to value or not in the games.

The content analysis aims to analyze numerically the frequency of citations of certain terms and references in a given text. Content analysis involves techniques that allow, in a systematic way, the description of messages and procedures related to the analyzed context, as well as the conclusions of the data that were collected [Flick 2008]. In this study, the content analysis was applied from the interview transcripts, and followed the steps proposed by [Flick 2008]:

1. Analyze each sentence and generate code(s) for it.

2. Review the codes, unifying those that express the same idea, and excluding those that are not relevant to the research objectives. An example of a code without contribution is In the game, everyone is a car.

3. Group codes that express related meanings into categories. In this work, a specific theory was not used to support the grouping.

4. Select examples for the codes and categories. In this study, extracts cited by the participants were selected to illustrate the analyses made.

\subsection{Creation of a Gamebook}

This activity consisted of the elaboration of a catalog with the information of some games. Ten games mentioned in the interview with girls who play were chosen. Eight of these games followed the positive characteristics identified in the analysis of the interviews, and characteristics found in the literature. Two games had attributes that are not valued by the girls, based on the analyzes performed, and were included in the Gamebook to validate the previous results.

\subsection{Gamebook Presentation}

The Gamebook was presented to ten girls from 15 to 24 years old, who do not have the habit of playing. The number of participants was also chosen according to [Guest et al. 2006], who indicated that considering a homogeneous group, six to 12 interviews may be enough to achieve the research goal. The same age range of the participants who have the habit of playing games was also maintained.

iSys: Revista Brasileira de Sistemas de Informação (iSys: Brazilian Journal of Information Systems) http://seer.unirio.br/index.php/isys/ 
Participants were recruited from technical courses, high school and universities, and the strategy used to invite participants was the "snowball" strategy, as in the stage of initial characteristics identification, based on the indication of girls by the research participants themselves.

A small interview was carried out with these girls to identify if they would be interested in knowing the games, what they liked or not within what was presented in the Gamebook, and if they would have any suggestions.

The interviews were semi-structured. The questions asked in the interviews can be found in the Appendix B.

\subsection{Analysis of interviews with girls who are not in the habit of playing games}

The method chosen for the analysis of the interviews was the content analysis described in Section 3.2. We aimed to validate if the characteristics mentioned in the initial interview with girls who play games are the same as those mentioned by girls who do not have the habit of playing. More characteristics that the participants indicated to value or not in a game were identified.

\subsection{Validation of analyzes}

To increase the validity of the results, a validation through triangulation was performed, for which another data collection instrument was used: a questionnaire. According to [Vergara 2006], triangulation can contribute to the validity of the research and can also be a means to reach new knowledge.

The questionnaire was made available for all genders, making it possible to verify distinct and common aspects identified in the qualitative analysis with the participants and a greater understanding of gender differences concerning what is valued in games. We sought to apply the same questions from the interviews conducted with girls who play games and girls who are not in the habit of playing. The questions presented in the questionnaire can be found in the Appendix C.

Using multiple sources can allow for better identification of inconsistencies, complementation, and knowledge about the results [Kelle 2001, Abdalla 2013].

\section{Results}

This section presents the results obtained, which includes the results of the analysis of the interviews with girls who play and with girls who are not in the habit of playing, and also the presentation of the Gamebook.

\subsection{Analysis results of the interviews with girls who play games}

This section presents the results of the analysis of the interviews with girls who play digital games. There were 20 interviews, 10 interviews with girls who are from the CS area, and 10 interviews with girls who are not from the CS area. The purpose of the interviews was to enumerate characteristics that the participants indicated to like or dislike in games, to understand what they would like to see in games and to identify if there is

iSys: Revista Brasileira de Sistemas de Informação (iSys: Brazilian Journal of Information Systems) http://seer.unirio.br/index.php/isys/ 
a relationship between the possible interest in following the computing area, for girls in other areas, and the contact of these girls with games.

The interviews were transcribed, organized, coded, and categorized. The coding and categorization process resulted in 81 categories and 105 codes. For better visualization, Table 1 shows the number of codes generated separated by each question addressed in the interviews.

Table 1. Number of codes per question - Initial Identification

\begin{tabular}{|l|c|}
\hline Question & Number of codes \\
\hline What games do you like to play? & 28 \\
\hline $\begin{array}{l}\text { About game X, what does this game have } \\
\text { that makes you like it? (Positive Characteristics) }\end{array}$ & 5 \\
\hline What games do you not like to play? & 5 \\
\hline $\begin{array}{l}\text { About game X, what does this game have that makes } \\
\text { you dislike it? (Negative Characteristics) }\end{array}$ & 8 \\
\hline $\begin{array}{l}\text { Are there any features that you would like to see in games that } \\
\text { you have not yet noticed in the games you are used to playing? (Suggestions) }\end{array}$ & 5 \\
\hline $\begin{array}{l}\text { Do you think that the fact of playing games influenced your } \\
\text { choice of a computing course? }\end{array}$ & 3 \\
\hline $\begin{array}{l}\text { Have you ever imagined yourself developing a game, just like the } \\
\text { games you like to play? }\end{array}$ & 3 \\
\hline $\begin{array}{l}\text { Have you had any contact with the computing area, in addition to your contact } \\
\text { with digital games? }\end{array}$ & 3 \\
\hline Have you ever been interested in following the computing area in any way? & 5 \\
\hline $\begin{array}{l}\text { If so, do you think the fact of playing has aroused this possible interest? } \\
\text { Why? }\end{array}$ & $\mathbf{1 0 5}$ \\
\hline Are you interested in knowing more about any area related to computing? & 5 \\
\hline Total & 5 \\
\hline
\end{tabular}

It was observed that from the 16th interview, there were no new contributions, in the sense that no new codes or categories were generated.

From the total frequency of each code, it was possible to observe important issues that cover new points of view or reinforce what exists in the literature. For example, as characteristics pointed out as valued in a game, aspects related to social interaction and relationships, such as being able to play in a group, which were already mentioned by [Schultheiss 2017, Ochsner 2015, AlSulaiman and Horn 2015, Fortim et al. 2016, DeleAjayi et al. 2018] and [Bergstrom 2019]

Some of the codes eliminated for not bringing contributions were related to the following sentences: In the game, everyone is a car and Games not available for all devices.

\subsubsection{Characteristics that the participants indicated they like in games}

Participants were asked which games they like to play most, and the games most cited were from the categories of simulation games, drawing, sports, adventure, and multiplayer online battle arena (MOBA), which are games where the player controls the character in 
a battle between two teams. In the simulation category, The Sims was the most mentioned (five times); in the drawing category, it was the game Gartic, mentioned four times; in the MOBA category, it was League of Legends game, also mentioned four times; in the sports category, FIFA game was mentioned three times; and in the adventure category, the game Life is Strange was also mentioned three times. It is interesting to note that all games have the characteristic of being multiplayer, a characteristic that proved to be important for the participants when asked about what they like most in the games they like to play. Several girls cited more than one game. In total, 32 games were cited.

The participants also explained why they liked the games they mentioned. Figure 2 summarizes the cited characteristics, in which the characteristics are represented by the generated codes.
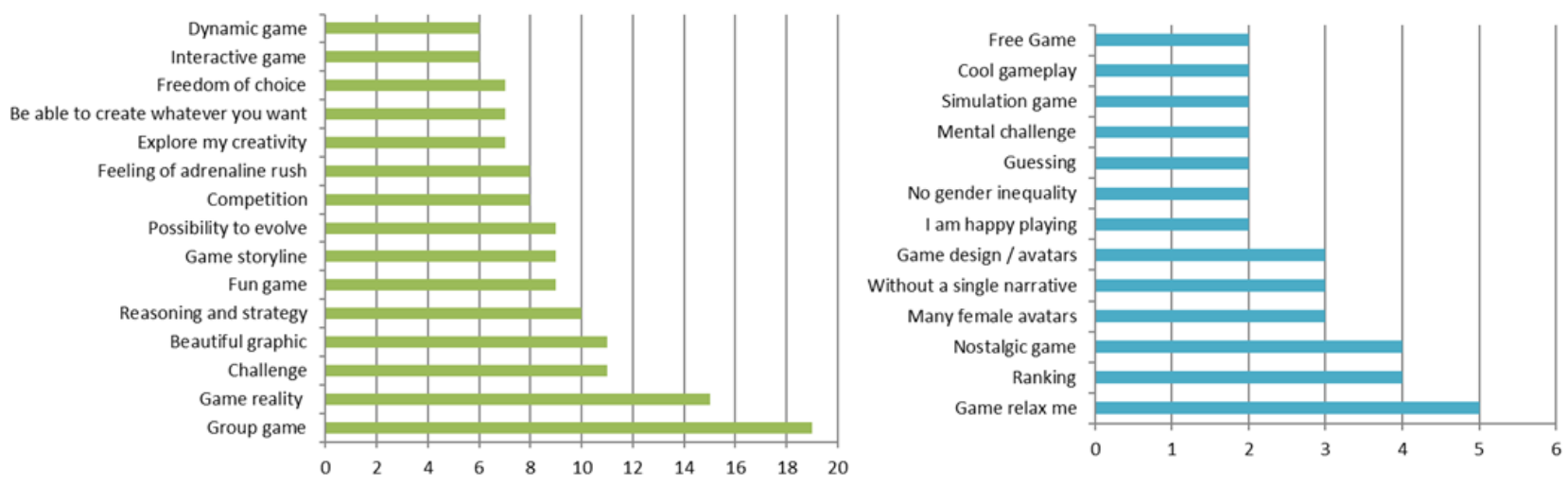

Figure 2. Positive characteristics - Initial identification (On the left, characteristics with at least six mentions. On the right, characteristics with at most five mentions.)

Since the most frequently cited games have the characteristic of being multiplayer games, this aspect can be signaled as the most valued by the interviewees. The category Group game had 25 occurrences of its codes. The following sections illustrate how the girls visualize the interaction with friends and colleagues in the games:

"I think it's cool that you play and interact with the people you're playing, like status, you compete based on friendship, real interaction, I think that attracts me."

( $P 2,16$ years old, plays once a week)

An interesting point that can be observed is the characteristic Game reality, in which the interviewees cited characteristics not only focused on the realistic graphics, but also in the sense of simulating real-life, managing everyday situations. For this, the category Game reality was created, which includes the characteristics Simulation game and Game reality, totaling 15 occurrences. It was observed that for the participants it is important to get out of the routine and experience something different within the game, but they also like to be able to set up their homes, raise their families, and build characters with hair, makeup and clothes however they want.

iSys: Revista Brasileira de Sistemas de Informação (iSys: Brazilian Journal of Information Systems) http://seer.unirio.br/index.php/isys/ 
"I think the simulation game I like a lot, its gameplay is cool like it has a lot of options, the game can follow several different paths according to what you choose."

(P5, 24 years old, plays every day)

The aesthetics and design of the game are also characteristics valued by the participants. Within the category Game art, which includes Game design/avatars, Beautiful graphics occurred 11 times. It can be observed that seeing the reality and the beauty of a game let them impressed:

"The graphic is perfect, you look at the sun and it almost burns your eyes so real that it is [...] with a spectacular graphic, I said my God! It's very real, it has four seasons that leaves even fall on you when you're driving by, the leaves even move, it gives you a wonderful feeling."

$(P 7,18$ years old, plays every day)

Reasoning and strategy were also mentioned as characteristics that the interviewees value in a game and had the frequency of ten occurrences. Other characteristics cited were Interactive Game, with six occurrences, and Dynamic Game, with seven occurrences. The Freedom of choice feature is linked to other features like Explore my creativity and Be able to create whatever you want, both with seven occurrences each. These characteristics include questions such as being able to decide the path the character will take and the autonomy to build what he wants.

Another interesting characteristic cited by three girls is related to female avatars in the game, such as Many female avatars.

"In a game that brings many women to me, like League of Legends, it is because there is a lot of communication, there is a lot of female characters, which brings a better relationship [...] and I like all the characters too, everyone is very charismatic, fun, and there is a character who is a gamer, she plays, she was the best player in Korea, and she was hired to pilot a robot within the game, and I think it is very incredible."

( $P 7,18$ years old, plays every day)

The Game storyline characteristic had nine occurrences and some girls described this characteristic as the first sign of whether or not they will like the game: if it is a story that holds them, it makes them want to go through the game and find out consequences of that story. Still considering the storyline of game, it was mentioned by three participants that the characteristic Without a single narrative is also valued.

The characteristic Feeling of adrenaline rush was mentioned eight times and characteristics related to well-being were identified, such as Game relax me, with five occurrences, and I am happy playing, with two occurrences. The fact that the game reminds someone of childhood, or from the past, can also be considered. Four participants mentioned the characteristic Nostalgic game.

Finally, characteristics in games that attempt to establish an egalitarian environment were also addressed, and two girls cited the characteristic No gender inequality.

iSys: Revista Brasileira de Sistemas de Informação (iSys: Brazilian Journal of Information Systems) http://seer.unirio.br/index.php/isys/ 


\subsubsection{Characteristics that participants indicated they did not like in games}

Respondents were also asked which games they do not like to play. In this regard, many had difficulty finding a specific game that they already had contact with and did not like, but when they did not arrive at a specific name or type, they detailed the characteristics that did not attract their attention or did not make them feel free to play. Of the eight girls who listed games, they did not really like, the FreeFire, PUBG, CounterStrike, and Fortinite games had two mentions each. These games belong to the MOBA or first-person shooter category.

When the participants were asked what characteristics they dislike in a game, the aspects of Cruelty and Games with inappropriate content were the most mentioned: Cruelty with 12 occurrences and Games with inappropriate content with five occurrences. The interviewees who mentioned the Cruelty aspect pointed out that they did not like games that can work on indifference or pleasure in face of others suffering and pain. The feeling when listening to them is that it caused them great discomfort. Participants who mentioned Games with inappropriate content justified that what they dislike is a game with profanity and censored content. Shooting game was mentioned by four girls and two of them clarified that it would be the game genre whose only activity is to shoot other players. Figure 3 summarizes the mentioned characteristics.

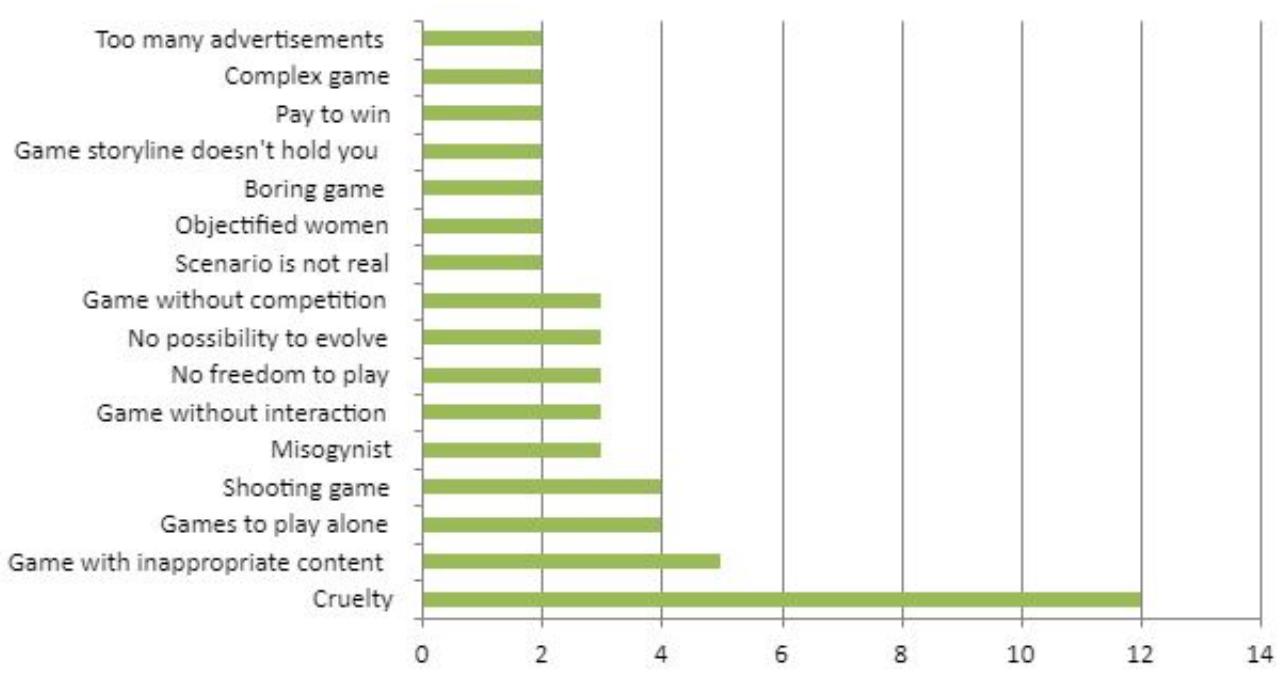

Figure 3. Negative characteristics - Initial identification

As can be seen in Figure 3, the characteristics with three occurrences were: Chauvinism, Games without interaction, No freedom to play, No possibility to evolve, and Game without competition. Concerning Chauvinism, three girls reported negative experiences in online games and explained that they did not participate in game chats because they are women, due to possible verbal aggression that may occur by some players who consider that a male environment. Two girls also cited the objectification of women within the game as an aggravating factor for disrespect among players.

"And then there are games that have this hostile environment too, men cursing, they think that just because you are a woman they can curse, they

iSys: Revista Brasileira de Sistemas de Informação (iSys: Brazilian Journal of Information Systems) http://seer.unirio.br/index.php/isys/ 
think that women don't play, that female players are always bad. Actually, we still need to improve a lot, it is still not so common to see women players easily, then men think Eh... it is her boyfriend playing, even more with MOBA games."

(P7, 18 years old, plays every day)

It is important to note that the mentions of the characteristic Games to play alone as a negative aspect reinforce the importance of the game being in a group, which was the positive characteristic most mentioned by the participants. This reinforcement also occurs with the characteristic Game without interaction, which was mentioned as an unappreciated characteristic, and interactive and dynamic games which were characteristics mentioned as positive. The same happens between the positive feature Competition and the negative feature Game without competition.

Finally, two girls mentioned that Pay to win makes them feel that they have no value in the game. They value competing, regardless of the result, knowing that winning depends only on their merit.

\subsubsection{Characteristics that participants would like to have in a game}

Another question of the interviews addressed suggestions for characteristics that participants would like to have in games. Figure 4 summarizes the presented suggestions.

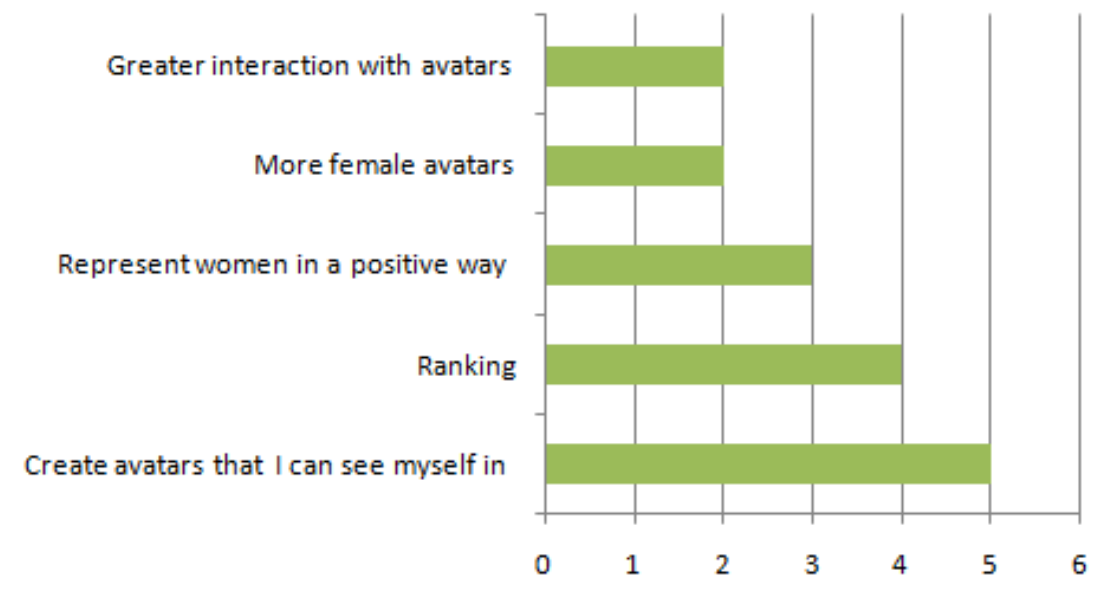

Figure 4. Suggestions presented - Initial identification

One can observe a relationship between the characteristics More female avatars and Create avatars in which I can see myself, with their physical characteristics represented, and not just stereotyped characters, such as strong and blond characters. Besides, three girls also mentioned that it is necessary to represent women positively in the games, not only inserting female avatars but also representing them in an unobjectified way, as happens in several games, a fact also commented on by [Vieira and da Mota 2018, Schultheiss 2017, Fortim et al. 2016, Gao et al. 2017, Shaer et al. 2017, Cerdera and Lima 2016, Dele-Ajayi et al. 2018, Bayde et al. 2019, de Amorim et al. 2016, Rosa et al.

iSys: Revista Brasileira de Sistemas de Informação (iSys: Brazilian Journal of Information Systems) http://seer.unirio.br/index.php/isys/ 
2018, Ansari et al. 2019, Araujo and Pereira 2017, Saláfia et al. 2018], and [Bristot et al. 2017], in which hypersexualization is described when representing female avatars.

"I would like more to see the female presence in games, as in Call of Duty.

In Fifa there are no female avatars, I can't choose an avatar that I could find myself, see me in the game."

(P1, 16 years old, plays once a week)

It is important to note that the suggestions of the participants reinforce the characteristics that the participants do not like, such as the negative characteristics Chauvinism and Objectified women, and the suggestion Represent women in a positive way.

\subsubsection{Relationship between interest in a computer science career and contact with games}

For the interviewees who are already in the CS area, it was asked whether the fact that they played games influenced the choice to pursue a career in CS effectively. Of the ten interviewees, seven indicated that the fact of playing influenced their interest, curiosity, and decision of starting a course in the field of CS. Four participants also cited that playing made them spend more time with the computer.

For the interviewees who are not in the technology area, some questions were proposed to understand whether there is possible interest in knowing the area, or if this idea had already been at least considered, so it is possible to better understand the relationship between games and career.

Seven girls indicated that they had already had contact with the CS area. Contact through professional courses was the most frequent aspect, with four citations. The contact with their personal computers/cell phones and reading texts about CS were also mentioned. It was mentioned that technology is a very demanding area and that to know or follow the area, one has to like it a lot. It was stated by four girls, that they never had an interest in following the area. However, they were interested in getting to know better the area as a whole. Finally, it was reported by two girls the admiration for CS professionals and the existence of an interest in having some kind of interaction with these people.

When asked if playing games aroused a possible interest in pursuing a CS career, six girls indicated that playing aroused an impulse to get to know the area, even though they did not choose it. Some points were mentioned concerning the influence of games, such as the fact that when one wants to explore, one can think about changing something in the game, it arouses curiosity, while playing, one can imagine how that game was developed, and that all these aspects can be evidence to develop an interest in the CS area.

"Yes, like, when I was playing, I wondered how it should work, here comes that curiosity even arouses at least interest."

(P6, 16 years old, plays every day)

It is important to highlight that other studies, such as [Hosein 2018] and [Martins et al. 2019], have already discussed the possible relationship between playing and pursuing a CS career. However, this work, in addition to reinforcing previous studies, sought

iSys: Revista Brasileira de Sistemas de Informação (iSys: Brazilian Journal of Information Systems) http://seer.unirio.br/index.php/isys/ 
to understand this relationship with girls who are already from the CS area and also with girls who are not, which is rarely addressed in other studies.

\subsection{Gamebook}

The Gamebook is a virtual catalog that made it possible to interview girls who are not in the habit of playing. Ten games were chosen to compose the Gamebook. They were presented in the Gamebook through the description of the game, its objective, genre, images, and videos for the participants to learn a little about them. Figures 5 and 6 show examples of Gamebook screens.
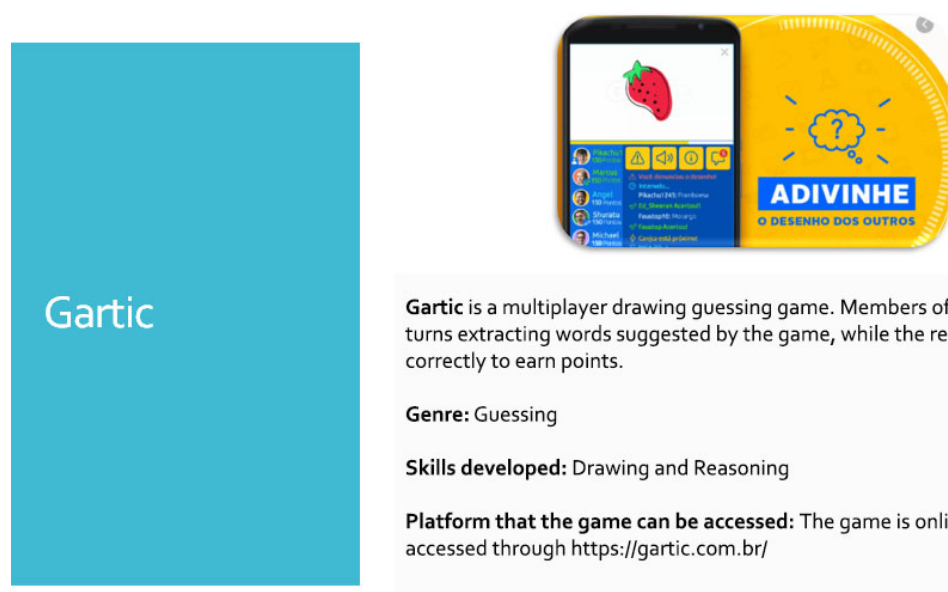

Gartic is a multiplayer drawing guessing game. Members of a room take turns extracting words suggested by the game, while the rest have to guess correctly to earn points.

Genre: Guessing

Skills developed: Drawing and Reasoning

Platform that the game can be accessed: The game is online and can be accessed through https://gartic.com.br/

Figure 5. Gamebook game description screen
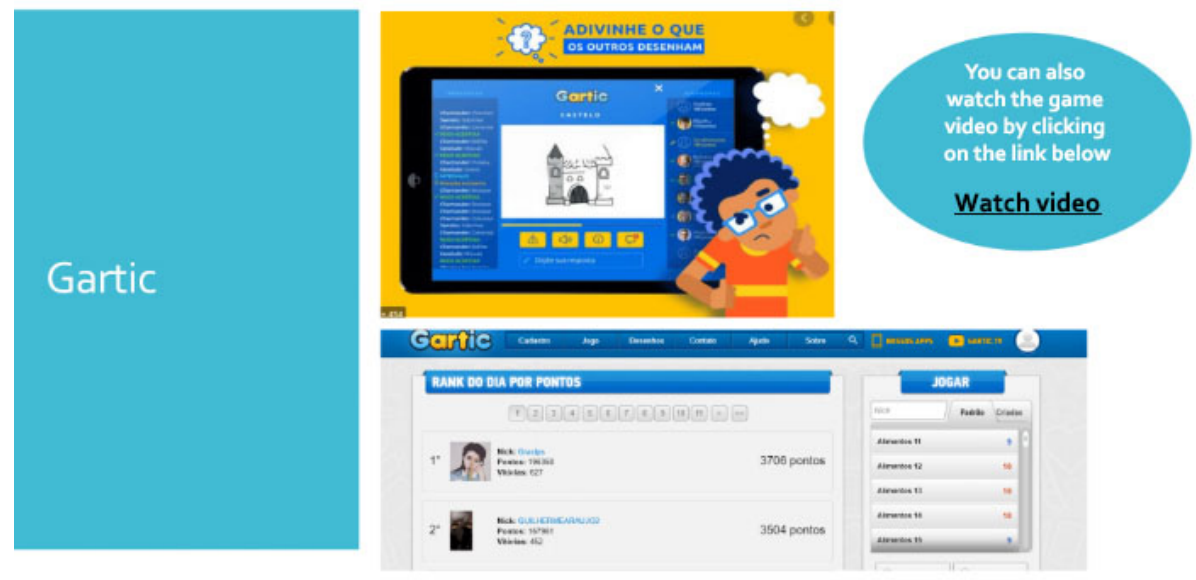

Figure 6. Gamebook game screenshots

[Schultheiss 2017, Ochsner 2015, AlSulaiman and Horn 2015, Fortim et al. 2016, Dele-Ajayi et al. 2018, Harrison et al. 2016], and [Bergstrom 2019] discussed the socialization and relationship aspect of games, and mentioned that there is a preference among girls for group games. Based on these characteristics, and considering the 
games most mentioned in the interviews, the games Forza, Injustice, League of Legends, Minecraft, Fifa, and Gartic were chosen to compose the Gamebook.

The Reality of the game characteristic was also mentioned by the participants, which is related to being able to live everyday situations. With this characteristic in mind, the games Life is Strange and The Sims were chosen, which can also be played in groups and provide players with freedom of decision.

From the analysis of the interviews with girls who play, it was possible to notice that characteristics such as Cruelty and Games without interaction, in which one plays individually, were mentioned as negative characteristics that the participants indicated they did not like within a game. This result coincides with previous discussions [Harrison et al. 2016, Gao et al. 2017, Desai et al. 2017, Kafai and Burke 2014, Kaufman et al. 2019], in which it was found that girls do not usually identify with games in which there are cruelty, extreme violence, and negative feedback on their actions. Given these characteristics, the games CounterStrike and FreeFire were chosen. The game FreeFire was also cited by some girls as a game that they do not like because it has a confusing plot and, therefore, they do not always understand its purpose.

\subsection{Analysis results of interviews with girls who are not in the habit of playing games}

This section presents the results of the analysis of interviews with girls who are not in the habit of playing games. The interviews were transcribed, organized, coded, and categorized. The coding and categorization process resulted in 31 categories and 35 codes. For better visualization, Table 2 shows the number of codes generated separated by each question addressed in the interviews.

Table 2. Number of codes per question - Gamebook presentation

\begin{tabular}{|l|c|}
\hline Question & Number of codes \\
\hline $\begin{array}{l}\text { Have you been interested in any game presented? } \\
\text { If so, which games? }\end{array}$ & 11 \\
\hline $\begin{array}{l}\text { About the game X, what aroused your } \\
\text { interest in the game? (Positive Characteristics) }\end{array}$ & 5 \\
\hline $\begin{array}{l}\text { What games are you not interested in knowing } \\
\text { more or playing? }\end{array}$ & 5 \\
\hline $\begin{array}{l}\text { Considering what was presented about game X, what made you } \\
\text { dislike the game? (Negative Characteristics) }\end{array}$ & 6 \\
\hline $\begin{array}{l}\text { What features do you find interesting and } \\
\text { suggest to have in a game? (Suggestions) }\end{array}$ & $\mathbf{3 5}$ \\
\hline Total & $\mathbf{2}$ \\
\hline
\end{tabular}

It was observed that from the seventh interview there were no new contributions, in the sense that no new codes or categories were generated.

From the total frequency of each code, it was possible to identify important issues that encompass new points of view or reinforce what exists in the literature, just as it happened when analyzing the interviews with girls who play games. In general, similarities of characteristics mentioned by participants who play games and participants who are not in the habit of playing could be observed.

iSys: Revista Brasileira de Sistemas de Informação (iSys: Brazilian Journal of Information Systems) http://seer.unirio.br/index.php/isys/ 


\subsubsection{Characteristics that the participants indicated they liked in the games pre- sented}

Starting the interviews, the participants were asked which games they were most interested in among what was presented on the Gamebook. The games mentioned were from the categories of drawing, simulation, racing, MOBA, fighting, adventure, battle, and sports, a result very similar to that of the girls who play games, except for the fighting category, which was mentioned only by girls who do not have the habit to play. In the drawing category, Gartic was mentioned six times; in the simulation category, the game The Sims, five. Forza and League of Legends were mentioned four times and belong to the racing and MOBA categories, respectively. The game Injustice, in the fighting category, was mentioned three times; and Life is Strange, FreeFire and Fifa games had two quotes each, and belong respectively to the adventure, battle game, and sports categories. It is interesting to note that most of the aforementioned games have the characteristic of being multiplayer, as happened when participants who are in the habit of playing mentioned games they like to play.

Figure 7 summarizes the characteristics that were mentioned, in which the characteristics are represented by the generated codes.

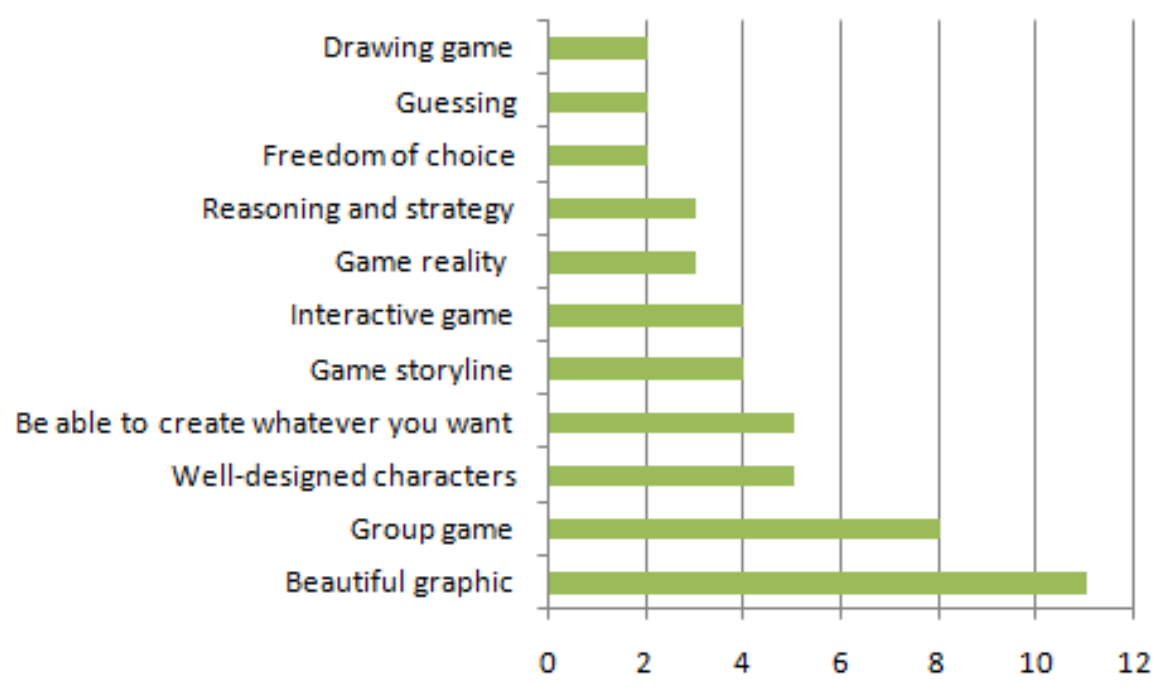

Figure 7. Positive characteristics - Gamebook presentation

When the participants were asked about what aroused their interest in the games they liked among the Gamebook options, the most cited feature was Beautiful graphic, present in the Game art category, and mentioned 11 times.

"Very beautiful graphic, it has game reality, it seems that you are inside the game, it gives that feeling of being part of the game."

$(P 1,24$ years old $)$

The most cited feature was Group game, mentioned eight times. Many girls expressed that they do not like games to play alone and that they think that playing with friends is always more interesting.

iSys: Revista Brasileira de Sistemas de Informação (iSys: Brazilian Journal of Information Systems) http://seer.unirio.br/index.php/isys/ 
"I like it because I can interact with my friends and play with them [...] I think because I can play with my friends, the game design is interesting, the characters were well designed."

$(P 4,16$ years old $)$

These characteristics are the same that were mentioned as valued by the participants who play games, except that for the participants who play, the characteristic Group game had the greater number of occurrences, and right after that are the characteristics related to the art of the game, and for participants who are not in the habit of playing, Beautiful graphic had more mentions than Group game.

Participants also cited the characteristics Well-designed characters and Be able to create whatever you want, with five mentions each. The characteristic Well-designed characters belongs to the category Game art, reinforcing the importance of the aesthetics of game for the participants. The fact of being able to make decisions within the game was also valued by the participants, as is the case with the characteristics Be able to create what you want and the Freedom of choice, which were mentioned by two girls. Characteristics related to freedom in the game were also cited by participants who play, demonstrating that they value in-game exploration, creativity, and decision-making power, as the freedom to choose avatars and paths that the game will follow.

"You can set things up your way, your own story; I can change some elements, I have freedom within the game."

(P6, 16 years old $)$

A characteristic mentioned four times by participants who are not in the habit of playing games is Game storyline. This reinforces the results presented by [Harrison et al. 2016], who stated that the characteristics that young women choose as favorites include a rich narrative. The characteristic Interactive game has also been mentioned four times.

Some girls commented on how much they liked the game Gartic and how this game brought together other characteristics they like, besides guessing. Two girls commented that they really like to draw and that this game can also be played with friends, making it even more interesting.

\subsubsection{Characteristics that the participants indicated they did not like in the games presented}

When asked about the games they were not interested in, the games with the most occurrences were from the sports and open-world categories, better known as Sandbox or games in which only minimal limitations are placed on the characters, battle, simulation, and shot. In the sports category, the game Fifa was mentioned five times and in the open-world category, the game Minecraft was mentioned four times.

For the participants who play games, the game Fifa was mentioned as a game they like because some interviewees like football and because it allows them to play with players they admire, in addition to the feeling of being really inside the game. The game Minecraft was also mentioned as a game they like, because they have the freedom to

iSys: Revista Brasileira de Sistemas de Informação (iSys: Brazilian Journal of Information Systems) http://seer.unirio.br/index.php/isys/ 
build whatever they want, and it was also mentioned as a game that relaxes. It is an interesting point of view because, for participants who are not in the habit of playing, the game Minecraft was mostly mentioned as a game that they have no interest in playing, as they consider that it has ugly and poorly made characters, for having a block layout and formed by pixels, designed to allow it to be possible to build what the player wants. This fact reflects the importance of a Beautiful graphic, which was the characteristic most mentioned by participants who are not in the habit of playing.

Participants also answered why they were not interested in the games they mentioned. Figure 8 summarizes the mentioned characteristics.

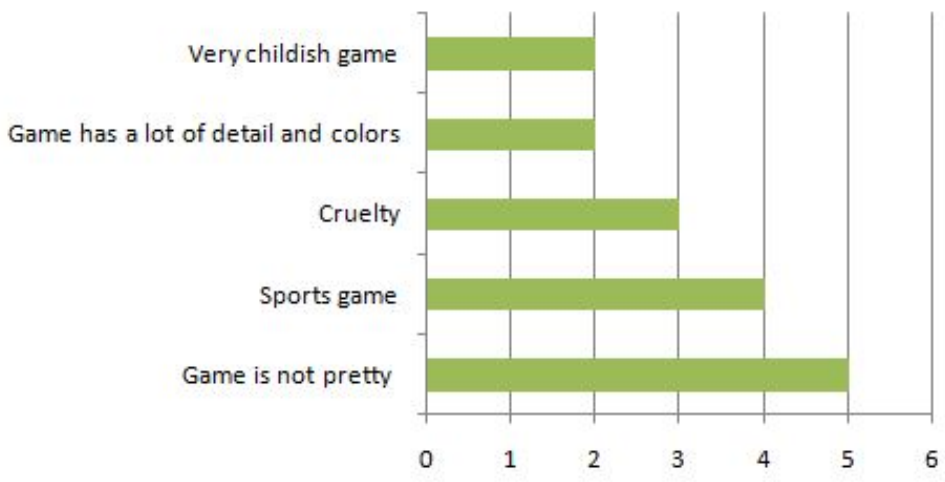

Figure 8. Negative characteristics - Gamebook presentation

The negative characteristic with more occurrences was Game is not pretty, with five mentions, classified in the Game art category. Other characteristics belonging to the category Game art were Game has a lot of detail and colors and Very childish game, with two mentions each, once again reinforcing the importance of game aesthetics for the participants.

Four participants mentioned Sports game as a negative characteristic and justified that they do not like football.

"Because I don't like football very much, I don't know how to play so it doesn't interest me."

$(P 9,19$ years old $)$

Similar to girls who play, the characteristic Cruelty was also mentioned by girls who are not in the habit of playing as an aspect that did not interest them in games.

\subsubsection{Characteristics that participants would like to see in a game}

Finally, the interviewees listed suggestions for games. Figure 9 summarizes the suggestions presented.

The suggestions were grouped into the categories Interactive games, Get out of the routine, Group game, Game art, and Games to distract yourself. More interactive games was a suggestion made by five participants.

\footnotetext{
iSys: Revista Brasileira de Sistemas de Informação (iSys: Brazilian Journal of Information Systems) http://seer.unirio.br/index.php/isys/
} 


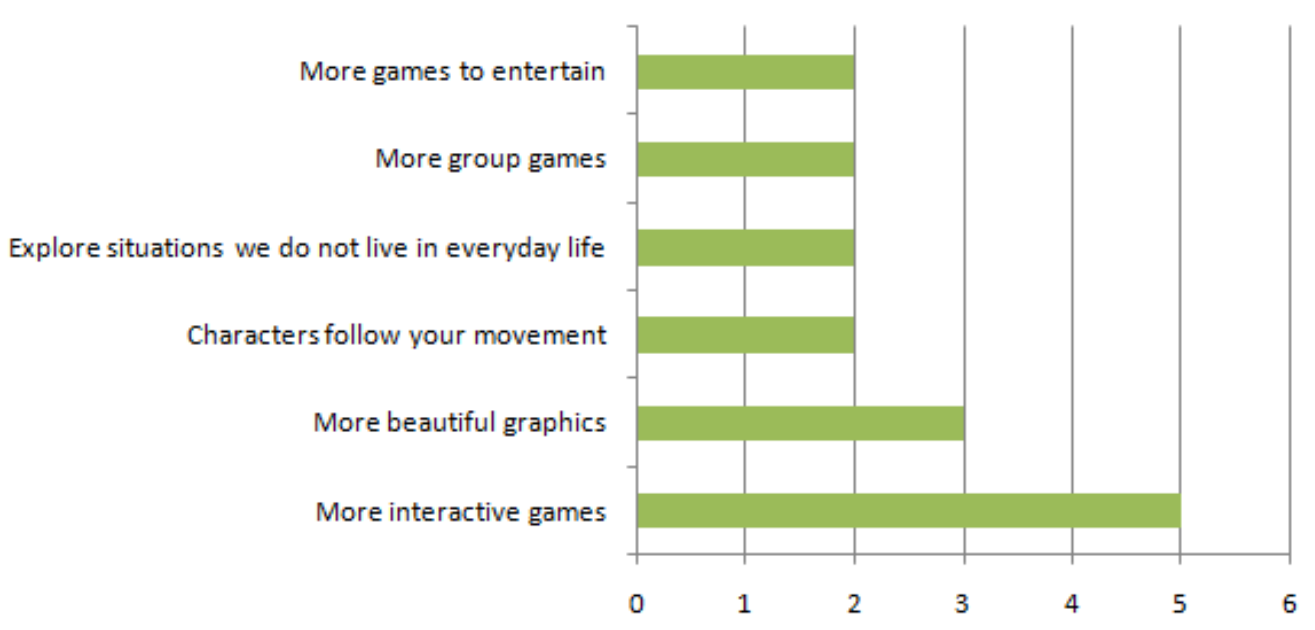

Figure 9. Suggestions presented - Gamebook Presentation

"Being able to make a video call in the games, it becomes more interactive, we should have more games to play in groups, to be able to interact with the elements of the game."

$(P 2,16$ years old $)$

More beautiful graphics was a suggestion made by three girls, reinforcing once again the importance of the aesthetics of game for the participants, as identified in the characteristics that the participants presented as being positive.

"I am very visual, so it would be a game with a very nice graphic, not too complex as a game that you have to read too much, that has too much instruction. I like the most practical games, one that hits me in the eye and I already know if I want to play it."

(P8, 21 years old $)$

The suggestions Explore situations we do not live in everyday life, More group games and More games to entertain were also presented, each of which was mentioned twice.

"I think the game has to make us escape from reality, it has to have elements and a story that we don't live even in our daily lives, new situations, situations that we are not used to."

$(P 7,21$ years old $)$

It is important to note that two participants commented on the dissemination of games, and indicated that the games for girls should be disseminated more, and perhaps how games are disseminated today is not the way that covers characteristics that girls value in them.

Some mentioned suggestions already exist in games available on the market. However, as the interviewees do not yet have more direct contact with games, in their opinion, their suggestions were new. In any case, the suggestions reinforce the positive and negative characteristics that were collected.

iSys: Revista Brasileira de Sistemas de Informação (iSys: Brazilian Journal of Information Systems) http://seer.unirio.br/index.php/isys/ 


\subsection{Validation of analyzes}

This section describes the validation process of the results, which involves triangulation and verification of the characteristics indicated as valued or not within the games identified in the qualitative analysis with the participants, allowing the identification of inconsistencies, complementation, and knowledge about the results [Vergara 2006, Kelle 2001, Abdalla 2013].

Data used for triangulation were extracted from a questionnaire made available for men and women. Questionnaire questions are presented in Section 3.6. The questionnaire received a total of 70 responses. 25 respondents identified themselves as women and 45 as men. It is important to emphasize that the questionnaire enabled the selection of other gender options, but the genders selected by the respondents were only male and female and, therefore, only a comparison between these two genders is mentioned throughout this section. If there were responses with different genders, these were also examined in all comparisons and analyses.

The questionnaire aimed to verify the characteristics identified in the qualitative analysis with the interviewees, and a greater understanding of gender differences concerning what is considered valued in games. The content analysis method was used, the same method used to analyze the interviews with the participants. Answers were organized, coded, and categorized. The coding and categorization process resulted in 67 categories and 137 codes. Tables 3 and 4 show the quantity of generated codes separated by each question addressed in the questionnaire. The results are presented grouped by gender, to facilitate the identification of common and distinct preferences for each gender.

Table 3. Number of codes per question - Validation (Male Gender)

\begin{tabular}{l|c}
\hline Question & Number of codes \\
\hline What games do you like to play? & 12 \\
\hline $\begin{array}{l}\text { What do these games have that makes you like them? } \\
\text { (Positive Features) }\end{array}$ & 28 \\
\hline What games do you not like to play? & 20 \\
\hline $\begin{array}{l}\text { What are these games about that makes you dislike them? } \\
\text { (Negative Features) }\end{array}$ & 7 \\
\hline $\begin{array}{l}\text { Are there any features that you would like to see in games that you have not } \\
\text { yet noticed in the games you are used to playing? }\end{array}$ & 4 \\
\hline $\begin{array}{l}\text { Do you think that the fact of playing influences the choice for a course in the } \\
\text { technology area? }\end{array}$ & $\mathbf{7 9}$ \\
\hline Total & \\
\hline
\end{tabular}

\subsubsection{Features that respondents indicated they liked about games}

Initially, participants were asked which games they like to play. For male respondents, the most cited games were from the sports categories, such as the game Fifa, with 11 citations; first-person shooter (FPS), like the game CounterStrike, with nine quotes; roleplaying game (RPG), like the game The Witcher, with six quotes; action and adventure, like the game GTA, with five quotes, together with the game League of Legends, from

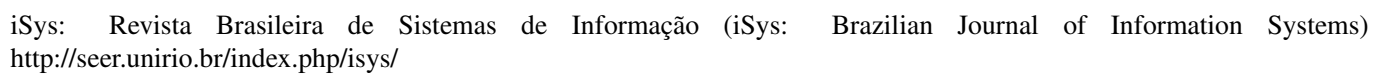


Table 4. Number of codes per question - Validation (Female Gender)

\begin{tabular}{l|c}
\hline Question & Number of codes \\
\hline What games do you like to play? & 15 \\
\hline $\begin{array}{l}\text { What do these games have that makes you like them? } \\
\text { (Positive Features) }\end{array}$ & 18 \\
\hline What games do you not like to play? & 3 \\
\hline $\begin{array}{l}\text { What are these games about that makes you dislike them? } \\
\text { (Negative Features) }\end{array}$ & 7 \\
\hline $\begin{array}{l}\text { Are there any features that you would like to see in games that you have not } \\
\text { yet noticed in the games you are used to playing? }\end{array}$ & 2 \\
\hline $\begin{array}{l}\text { Do you think that the fact of playing influences the choice for a course in the } \\
\text { technology area? }\end{array}$ & $\mathbf{5 8}$ \\
\hline Total &
\end{tabular}

the MOBA category, also with five quotes. Card games, real battle electronic games, and augmented reality categories were also mentioned.

For female respondents, the most cited games were from the MOBA categories, such as the game League of Legends, with four quotes, and simulation, such as the games Skyrim, with four quotes, and The Sims with three quotes. Soon after, came the games Don't Starve Together and Shadow of the Colossus, both in the action and adventure category, also with three quotes. Games in the categories shooting, survival, acting and real battle electronic game were also mentioned.

The Sports game category, the category of games most mentioned by men, did not appear in the responses of women. In general, the categories showed similarities, but with differences in the number of citations and games mentioned in each category.

Participants also explained why they liked the games that were mentioned. Figure 10 summarizes the characteristics mentioned, which are represented by the generated codes.

The characteristic mentioned as the most valued in a game by men was the group game ou multiplayer characteristic, with 34 citations, fact that has some divergence with the work of [Dele-Ajayi et al. 2018], in which it was mentioned that social interaction is an aspect little valued by boys. However, it is necessary to consider that the research was carried out during a period of social isolation due to the Covid-19 pandemic. Therefore, this result may have been influenced by the context. Some participants mentioned that they usually do championships with friends and that they enjoy this interaction, not liking to play alone. Group or multiplayer game was the second feature most mentioned by women.

"Being able to play with friends and other people online, being able to play in teams."

(P13, 18-24 years, Male)

"It's fun when we make a championship with friends [...] Play this alone is really bad."

(P10, 25-34 years, Male)

iSys: Revista Brasileira de Sistemas de Informação (iSys: Brazilian Journal of Information Systems) http://seer.unirio.br/index.php/isys/ 


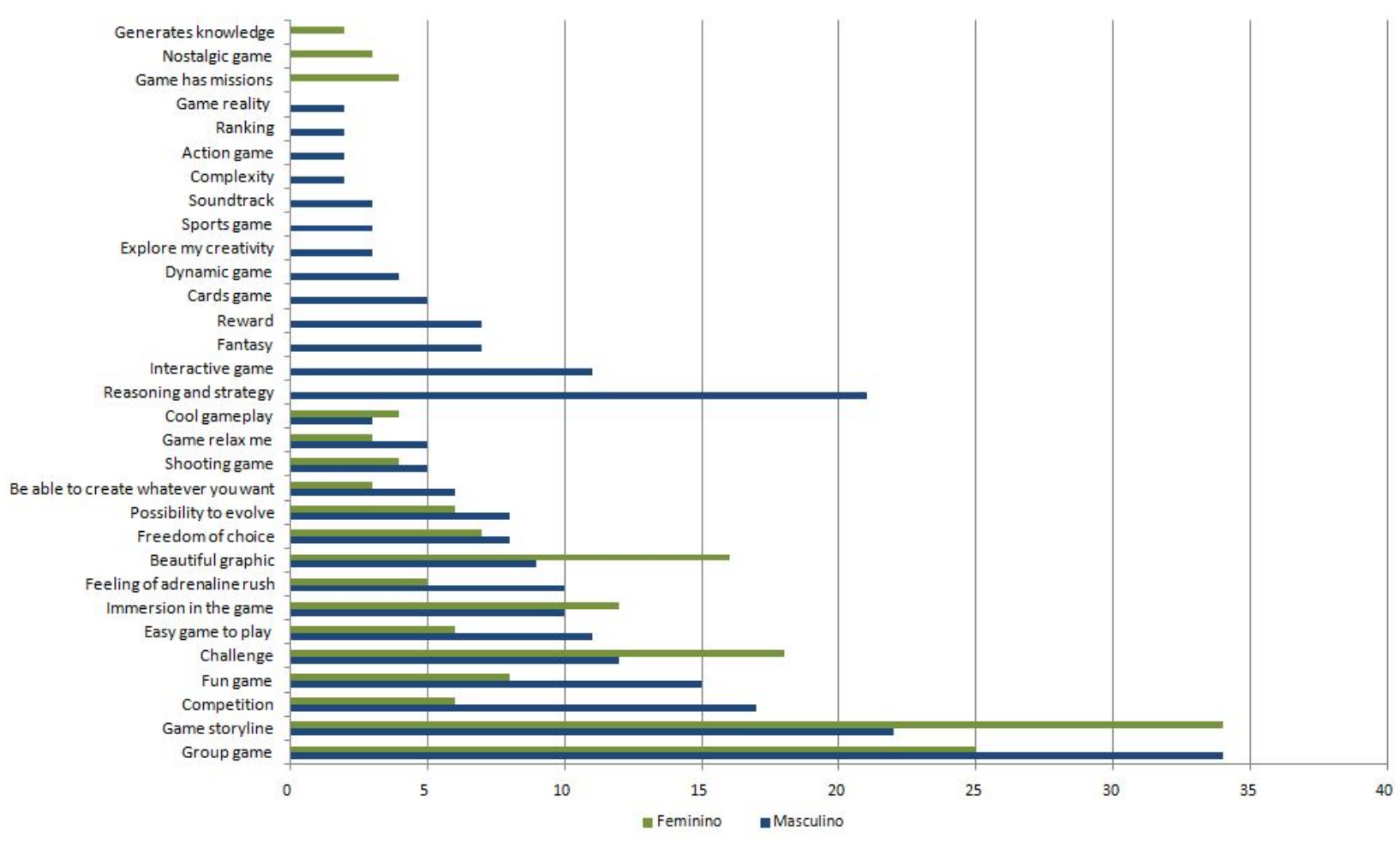

Figure 10. Positive Features - Validation

"I think so, the social aspect of a game is very interesting too. Games that you can play with a group of friends online or, especially, personally tend to please me a lot."

(P20, 18-24 years, Male)

"And I believe that when we put the group together to play, it's always fun.”

(P60, 18-24 years, Female)

The Game storyline feature was mentioned as a feature valued by male respondents, with 22 citations, and was the most cited aspect by female respondents, with 34 citations. Men also cited 7 times the Fantasy feature, which is an aspect encompassed by the storyline of game.

Characteristics related to the ease of play and interaction were also mentioned. The features Easy game to play and Interactive game had 11 quotes each. It is interesting to point out that the Complexity aspect had two citations, demonstrating different preferences of the participants, either for games that are easier to play or for games that may already have a higher level of complexity.

The aesthetics of game and visuals are also characteristics indicated as valued by the participants. The Beautiful graphic aspect had nine citations.

Characteristics related to freedom and autonomy within the game were also mentioned by male respondents. The Freedom of choice feature had eight quotes, the Be able to create whatever you want aspect had six quotes, and the Explore my creativity aspect 
had three quotes.

It can also be observed that some participants indicated that they value or not a game based on its genre. Five participants indicated that they like the games they mentioned because the game is a card game; five, because they were shooting games; and three, because they were sports games.

Finally, with two quotes each, the features Ranking, Action game, and Game reality appeared.

For women, characteristics related to freedom within the game, the well-being that the game provides, a sense of adrenaline, and evolution in the game were also mentioned, as can be seen in Figure 10.

The Shooting game feature had four citations, and the fact that this aspect was cited as valued by the respondents has some divergence with the works of [Dele-Ajayi et al. 2018, Desai et al. 2017, Fortim et al. 2016, Gao et al. 2017, Harrison et al. 2016, Kafai and Burke 2014, Kaufman et al. 2019] and [Schultheiss 2017], in which it was mentioned that girls prefer non-violent games. It is important to note that in those works it was not indicated what was considered violence for girls, and what type of violence was not their preference. Once again, it is necessary to emphasize that the interest of some women in games and non-violent or competitive themes should not be generalized, as this fact can further reinforce stereotypes about the interests of female players [Jenkins 1998].

As for the games cited as the ones they more like to play, the characteristics cited as aspects that lead participants to like the games have differences in the number of citations when comparing the results by gender, and some characteristics only appear for a specific gender. Table 5 presents a comparison of the characteristics mentioned by gender.

Table 5. Comparison by gender - Positive characteristics

\begin{tabular}{|l|l|l|}
\hline Common aspects & $\begin{array}{c}\text { Aspects mentioned only } \\
\text { by men }\end{array}$ & $\begin{array}{c}\text { Aspects mentioned only } \\
\text { by women }\end{array}$ \\
\hline Competition & Complexity \\
Challenge & Explore my creativity & \\
Game storyline & Fantasy & \\
Beautiful graphic & Action game & \\
Immersion in the game & Cards game & \\
Cool gameplay & Sports game & Generates knowledge \\
Shooting game & Dynamic game & Nostalgic game \\
Fun game & Interactive game & Game has missions \\
Group game & Reasoning and strategy & \\
Easy game to play & Ranking & \\
Game relax me & Game reality & \\
Freedom of choice & Reward & \\
Be able to create whatever you want & Soundtrack & \\
Possibility to evolve & & \\
Feeling of adrenaline rush & & \\
\hline
\end{tabular}

It can be seen that the characteristics mentioned only by men are mostly linked to the complexity, narrative, and genre of the game. The characteristics mentioned only by

iSys: Revista Brasileira de Sistemas de Informação (iSys: Brazilian Journal of Information Systems) http://seer.unirio.br/index.php/isys/ 
women, on the other hand, consist of characteristics related to the nostalgia that the game can provide, its missions, and the fact that it can add knowledge.

The characteristics mentioned by the respondents of the female and male gender were also compared with the characteristics mentioned in the interviews with girls who play games. In general, the characteristics that had the highest number of citations for respondents who play were common for male and female respondents of the questionnaire, including Competition, Challenge, Game storyline, and Group game, reinforcing the appreciation of these aspects for the participants who mentioned them. On the other hand, characteristics mentioned only by one group can also be observed, such as the Free Game aspect, cited only by interviewees who play, Fantasy, an aspect cited only by male respondents, and Generates knowledge, an aspect mentioned only by female respondents.

A comparison was made between characteristics mentioned by the respondents to the questionnaire and those interviewed who play games and the characteristics mentioned by those interviewed who do not have the habit of playing. Similar to the previous comparison with the interviewees who play games, characteristics that had a significant number of citations by the interviewees who do not have the habit of playing were common for the respondents to the questionnaire, such as the Game storyline, Beautiful graphic, Group game, and aspects related to freedom within the game. In this way, it is possible to visualize once again the reinforcement of these characteristics, mentioned as valued within a game. Some differences can also be pointed out, such as the Guessing aspect, mentioned only by the interviewees who are not in the habit of playing games; Soundtrack, an aspect mentioned only by male questionnaire respondents and Game has missions, an aspect mentioned only by female questionnaire respondents.

Common features mentioned by the interviewees and the questionnaire respondents can be seen as relevant aspects for this work, namely: Competition, Challenge, Game storyline, Beautiful graphic, Fun game, Group game, Game relax me, Nostalgic game, Freedom of choice, Be able to create whatever you want, Possibility to evolve and Feeling of adrenaline rush. Thus, with the application of the questionnaire and data triangulation, it was possible to validate characteristics indicated as valued in games, such as the Group game and Beautiful graphic aspects, and identify new learnings, as happens with new generated codes from the application of the questionnaire, such as the Generates knowledge feature.

\subsubsection{Features that respondents indicated they dislike about games}

Participants were asked which games they do not like to play. For male respondents, the most cited games were from the following categories: sports, such as the game Fifa, with nine citations; MOBA, like the League of Legends game, with eight quotes; shot, like the CounterStrike game, with four quotes, and the Valorant game, with two quotes. Games from the simulation, role-play, and real battle electronic game categories were also mentioned. It is interesting to observe the distinction of preferences when comparing the games they most like to play and the games they least like to play, such as the Fifa game, cited by nine respondents as a game they do not like to play, and cited by 11 respondents

\footnotetext{
iSys: Revista Brasileira de Sistemas de Informação (iSys: Brazilian Journal of Information Systems) http://seer.unirio.br/index.php/isys/
} 
as a game they like to play. The same scenario happens with the game CounterStrike, demonstrating how there can be this distinction of opinions regarding what people who play the game may or may not like.

For female respondents, the categories mentioned were MOBA, sports, and shooting, and all the games mentioned by them were also mentioned by male respondents. In the MOBA category, the game League of Legends had six citations; in the sports category, the game Fifa had five citations; and in the shooting category, the game CounterStrike had four citations.

Participants also explained the reason for not liking the games that were mentioned. Figure 11 summarizes the characteristics mentioned, and they are represented by the generated codes.

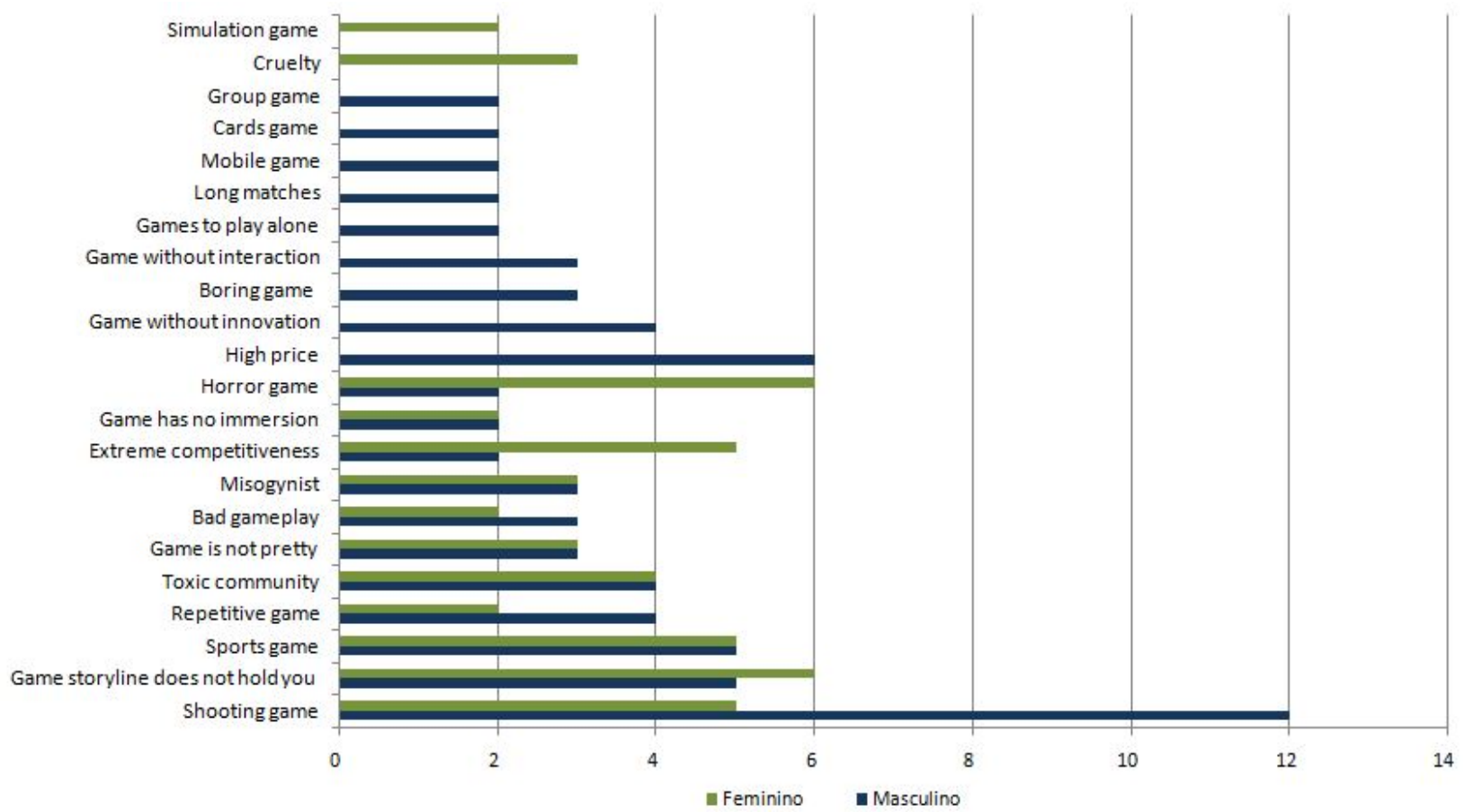

Figure 11. Negative Features - Validation

The feature most cited as an aspect not valued in games by men was Shooting game, with 12 citations by men, and five citations by female respondents. It is worth noting that one participant added the fact that he does not like shooting games because he does not think it is interesting where the only action of the character of game is shooting:

"Just running and shooting, no story, no development, no plot, I think it is so boring."

(P20, 18-24 years, Male)

High price was also a feature cited by six male participants as something they did not like in games. The feature Sports game had five citations, followed by the aspects Repetitive game, Game without innovation and Toxic community, with four citations each. Respondents who mentioned the Toxic community aspect demonstrated disapproval of

iSys: Revista Brasileira de Sistemas de Informação (iSys: Brazilian Journal of Information Systems) http://seer.unirio.br/index.php/isys/ 
the behavior of some people in the game and commented on aggressive and prejudiced actions that take place in communities of various games, and on the interaction between people at the time they are playing. Three respondents also cited the Misogynist aspect as something bad within games.

It is necessary to emphasize that different points of view of each respondent can be visualized once more with the characteristics Group game and Games to play alone, with two citations for each characteristic. These characteristics can be seen as opposites and were cited by different respondents.

For female respondents, the characteristics most cited as not valued in a game were Game storyline does not hold you, with six quotes, Horror game, also with six quotes, and the characteristics Extreme competitiveness, and Sports game, with five quotes each. It is worth noting that the Competition was an aspect indicated as valued by the participants, but the exaggerated competition and great rivalry in the game is no longer a preference.

"I think it's too instantaneous, I like the game that allows me to participate in the story and the world where it takes place."

(P13, 18-24 years, Female)

The characteristic Toxic community was mentioned by four girls, and Misogynist was mentioned by three, and they described situations experienced in some games:

"The bad behavior of some people in the game: lack of patience with beginners, trolling, bullying, and misogynist when you're a female player." (P23, 25-34 years, Female)

"Very strong competition and occasionally aggressiveness from other players in chats."

(P24, 18-24 years, Female)

"I also don't like online games where people in the game let themselves be affected by competitiveness and become aggressive."

(P57, 18-24 years, Female)

To demonstrate the characteristics cited in common or cited by only one group, Table 6 presents the comparison of the characteristics cited by gender.

It can be observed that the characteristics in common correspond, for the most part, to the characteristics most cited by both genders. Aspects cited by only one genre were identified, but they correspond to characteristics that have between two and three citations, except for the High price aspect, with six citations only from male respondents.

The characteristics mentioned by the male and female questionnaire respondents were also compared with the characteristics mentioned by the interviewees who play. The features Game storyline does not hold you, Shooting game and Misogynist were reinforced, being cited by respondents who play and respondents to the questionnaire. The Cruelty aspect was also reinforced, cited by the interviewees who play and by the female questionnaire respondents. Other aspects were mentioned only by one group, as with Scenario is not real, mentioned only by interviewees who play; High price, cited only

iSys: Revista Brasileira de Sistemas de Informação (iSys: Brazilian Journal of Information Systems) http://seer.unirio.br/index.php/isys/ 
Table 6. Comparison by gender - Negative characteristics

\begin{tabular}{|l|l|l|}
\hline \multicolumn{1}{|c|}{ Common aspects } & \multicolumn{1}{|c|}{$\begin{array}{c}\text { Aspects mentioned only } \\
\text { byen }\end{array}$} & $\begin{array}{c}\text { Aspects mentioned only } \\
\text { by women }\end{array}$ \\
\hline $\begin{array}{l}\text { Extreme competitiveness } \\
\text { Game storyline does not hold you }\end{array}$ & $\begin{array}{l}\text { Cards game } \\
\text { Group game } \\
\text { Bad gameplay }\end{array}$ & \\
Sports game & Boring game & \\
Horror game & Game without innovation & Cruelty \\
Shooting game & Game without interaction & Simulation game \\
Game is not pretty & Games to play alone & \\
Game has no immersion & Long matches & \\
Repetitive game & High price & \\
Misogynist & & \\
\hline
\end{tabular}

by male questionnaire respondents and Simulation game, cited by female questionnaire respondents. It is noteworthy that when analyzing the responses to the questionnaire, new codes were created, codes referring to characteristics not yet mentioned by the interview participants, such as the Toxic community characteristic.

Just as the characteristics mentioned by the questionnaire respondents were compared with those interviewed who play games, the answers were also compared with those interviewed who do not have the habit of playing. Similar to the previous comparison with the interviewees who play games, characteristics mentioned by the participants who do not have the habit of playing were reinforced, were also mentioned by the questionnaire respondents. It is interesting to note that the characteristics most mentioned by the interviewees who are not in the habit of playing, such as Game is not pretty, cited by five girls, was an aspect in common with the female questionnaire respondents, as well as Sports game, with four quotes. Cruelty was also a common aspect, cited by three interviewees and also by female respondents. Some differences can also be pointed out, such as the Very childish game aspect, a characteristic mentioned only by interviewees who are not in the habit of playing games; Long matches, an aspect mentioned only by male questionnaire respondents, and the Simulation game aspect, mentioned only by female questionnaire respondents.

Common characteristics mentioned by the interviewees and the female questionnaire respondents can be seen as relevant aspects for this work, namely: Cruelty, Game storyline does not hold you, Sports game, Shooting game, Game is not pretty and textitMisogynist. Thus, with the application of the questionnaire and data triangulation, it was possible to validate aspects indicated as not valued in games, such as Cruelty and Game is not pretty, and identify new knowledge, as happens with new codes generated from the application of the questionnaire, such as the Horror game feature.

\subsubsection{Features respondents would like to see in a game}

Another question addressed what features participants would like to see in games that they might not have seen yet. Figure 12 summarizes the characteristics cited by respondents.

iSys: Revista Brasileira de Sistemas de Informação (iSys: Brazilian Journal of Information Systems) http://seer.unirio.br/index.php/isys/ 


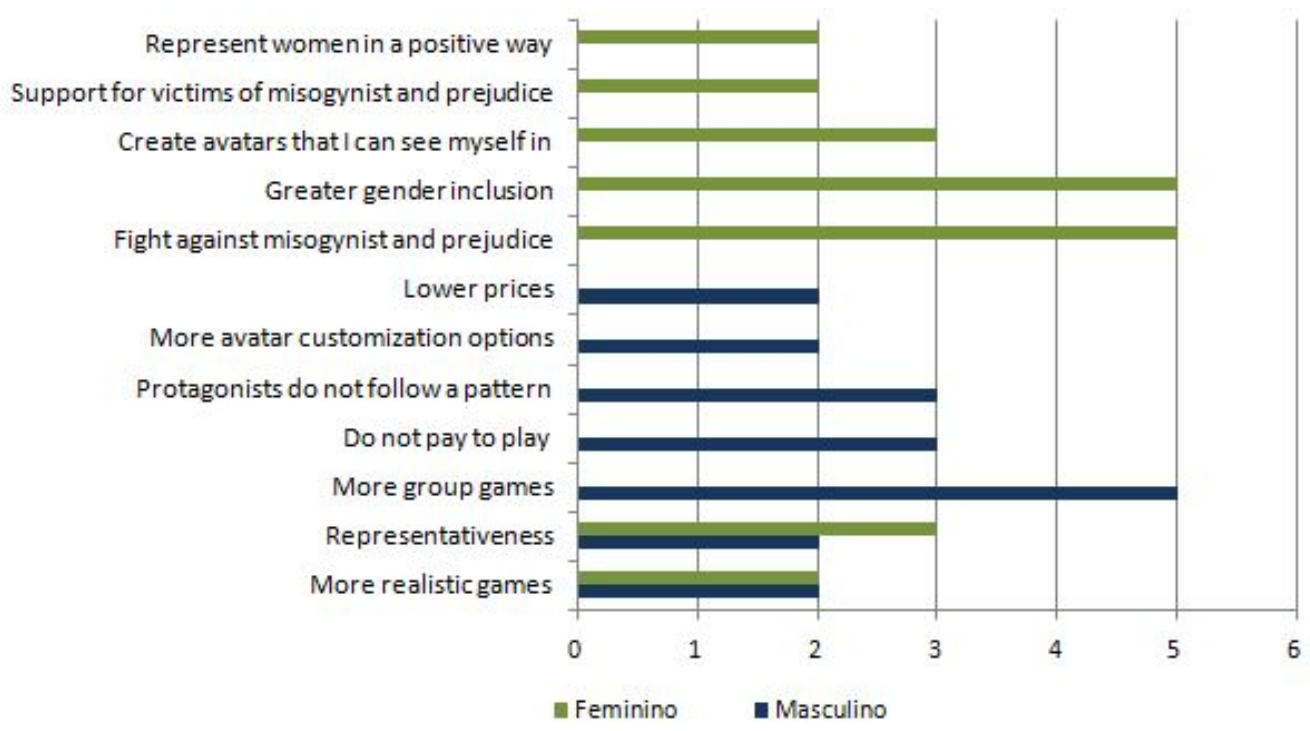

Figure 12. Suggestions cited - Validation

The suggestion most cited by male respondents was More group games, with five citations. Other characteristics mentioned include aspects such as inclusion in games, such as the characteristic Protagonists do not follow a pattern, mentioned by three participants, and Representativeness, mentioned by two participants.

"Representativeness is always a good thing. If I don't have an action/adventure game protagonist other than a standard 30-year-old white man, I'll be happy."

(P10, 25-34 years, Male)

Features related to high game prices and the possibility of not paying to play were also mentioned, such as the features Do not pay to play, with three quotes, and Lower prices, with two quotes.

For the female questionnaire respondents, the characteristics basically refer to the inclusion of gender in games. Fight against misogyny and prejudice and Greater gender inclusion had five quotes each. Other aspects related to inclusion in games and fighting prejudice were also mentioned, such as Create avatars that I can see myself in and Representativeness, with three citations for each aspect; Support for victims of misogynist and prejudice and Represent women in a positive way, with two citations each. It was possible to see in some excerpts of the answers of participants how much inclusion and combating aggressive, misogynist actions or those that demonstrate any kind of prejudice are necessary, as this can drive girls away from games, and makes the community toxic, an aspect also mentioned as a negative feature in games.

"Maybe some feature that helps combat the misogynist present in these predominantly male-played games."

(P12, 18-24 years, Female)

"Perhaps, I would say, games with more representative females characters, without sex appeal. I also miss stricter penalties for homophobic,

iSys: Revista Brasileira de Sistemas de Informação (iSys: Brazilian Journal of Information Systems) http://seer.unirio.br/index.php/isys/ 
sexist, and racist toxic actions. And support for victims of such aggressions."

(P60, 18-24 years, Female)

Finally, the More realistic games feature was cited, with two citations. It was the only aspect not related to the other suggestions, which mostly represented issues related to inclusion and representativeness in games.

The suggestions cited by each gender have differences and some similarities, as can be seen in Table 7, which presents the comparison of the aspects cited by each gender.

Table 7. Comparison by gender - Suggestions cited

\begin{tabular}{|c|c|c|}
\hline Common aspects & $\begin{array}{l}\text { Aspects mentioned only } \\
\text { by men }\end{array}$ & $\begin{array}{l}\text { Aspects mentioned only } \\
\text { by women }\end{array}$ \\
\hline $\begin{array}{l}\text { More realistic games } \\
\text { Representativeness }\end{array}$ & $\begin{array}{l}\text { More group games } \\
\text { More avatar customization } \\
\text { options } \\
\text { Do not pay to play } \\
\text { Lower prices } \\
\text { Protagonists do not follow a } \\
\text { pattern }\end{array}$ & $\begin{array}{l}\text { Support for victims of misogyny } \\
\text { and prejudice } \\
\text { Fight against misogyny } \\
\text { and prejudice } \\
\text { Create avatars that I can see } \\
\text { myself in } \\
\text { Greater gender inclusion } \\
\text { Represent women in a positive } \\
\text { way }\end{array}$ \\
\hline
\end{tabular}

It can be seen that only the features More realistic games and Representativeness were mentioned by both genders, and several aspects were mentioned by only one group. Keeping these differences in view, it is possible to identify that each gender has their own needs concerning what they would like to see in games. These needs can be seen as a result of what each gamer experiences, as happens with women, for example, who want to be represented positively, and who fight against misogyny and prejudice, combined with support for victims of these actions. For men, there is a suggestion that the protagonists of the games do not follow a specific pattern, as mentioned by a participant that in action and adventure games it is somewhat common to find protagonists following the pattern of being white, with the mean age also defined.

The suggestions cited by respondents of the female and male gender were also compared with the suggestions cited by the interviewees who play. In general, the suggestions that had the highest number of citations for interviewees who play were common for female questionnaire respondents, such as Create avatars that I can see myself in, cited by five interviewees, and Represent women in a positive way, cited by three interviewees. On the other hand, suggestions mentioned only by one group can also be observed, as is the case with the Ranking aspect, cited only by interviewees who play, and More realistic games, an aspect mentioned only by female questionnaire respondents. Thus, more suggestions could be identified, aspects seen by the participants of this study as characteristics that could be seen in games, such as the Support for victims of misogyny and prejudice, and Fight against misogyny and prejudice, which were new suggestions identified from the application of the results validation questionnaire, which had not been mentioned by the interview participants. When comparing the suggestions mentioned by the interviewees who play games and by the male questionnaire respondents, it can be observed that

iSys: Revista Brasileira de Sistemas de Informação (iSys: Brazilian Journal of Information Systems) http://seer.unirio.br/index.php/isys/ 
there were no common aspects, and it is worth emphasizing once again new suggestions identified by the respondents.

Just as the suggestions mentioned by the questionnaire respondents were compared with those interviewed who play games, the answers were also compared with those interviewed who do not have the habit of playing. It can be observed that concerning the suggestions mentioned, only the More group games feature was mentioned in common, for the male questionnaire respondents, and suggestions were not mentioned in common with the female questionnaire respondents. Once again, it is worth emphasizing that new suggestions were identified, aspects not yet mentioned by the interview participants.

With the application of the questionnaire and data triangulation, it was possible to validate aspects indicated as suggestions for games, such as Create avatars that I can see myself in and Represent women in a positive way, which show relevant aspects, cited by the interviewees and the female questionnaire respondents, and to identify new knowledge, such as new codes generated from the application of the questionnaire, such as the Representativeness suggestion.

\subsubsection{Relationship between interest in computing and contact with games}

Finally, the questionnaire also addressed a question about the relationship between games and technology, asking whether the respondent believes that the fact of playing could influence the choice of a course in the technology area. Analyzing the answers, 32 male respondents believe that it can influence, and 13 male respondents believe that there is no relationship between playing and pursuing a career in the technology area. Two participants mentioned that they chose the Digital Games course because they are used to playing games, and two mentioned that they chose the Computer Science course because they are used to playing games.

"I think so, many people choose the game development area because they have contact with them since they were young."

(P35, 18-24 years, Male)

For the female respondents, 18 participants believe that there is some relationship, and six respondents believe that playing does not influence their choice.

"For sure. A lot of people are interested in this area and this interest can come from playing games. When playing a game, anyone can be interested in the process that had to happen for that game being the way it is."

(P12, 18-24 years, Female)

"Yes, it happened in my case, and my brothers and many friends also went down the same way."

(P64, 25-34 years, Female)

This scenario of the largest number of participants believing that playing can influence them to choose courses focused on the technology area also happened with the participants in the initial identification interviews. Seven of the ten participants who are

iSys: Revista Brasileira de Sistemas de Informação (iSys: Brazilian Journal of Information Systems) http://seer.unirio.br/index.php/isys/ 
already from the area indicated that the fact of playing influenced their choice, and six of the ten participants who are not from the area indicated that the fact of playing sparked an impulse to learn more about the technology area.

\section{Conclusions}

This work aimed to propose adaptations in digital games, to attract more girls to play them. From the analysis of the interviews carried out with girls who play games, it was possible to identify characteristics that the participants indicated to like or dislike, what they would like to see in games, and to better understand the relationship between playing games and the interest in following a CS career. The participants indicated that they value the interaction and the design of the games, the fact that they can play in groups, and the possibility of simulating real-life or getting out of the routine. It can also be seen that games that involve cruelty and inappropriate content are characteristics indicated as not valued by them, and aspects such as misogynist within the games need to be avoided, to effectively guarantee the inclusion of more girls in this universe.

It was observed that most of the participants believe that there is a relationship between playing games and pursuing a CS career, even when this factor was not a decisive one to choose the area, as the fact of playing can develop an interest in at least knowing better the area. Many participants perceive this relationship because they know people close to them who played games and started a CS course, or believe that games generate curiosity and at the same time this can also boost interest in the area. However, all of this must be seen carefully, as this relationship does not always happen, and it is necessary to take into account other factors besides having contact with games to effectively decide to choose a CS career.

Given the analysis of interviews with girls who are not in the habit of playing games, several important points could be observed, not all equal to those mentioned by the girls who play. In general, game graphics, the possibility of playing in a group, the reality of the game, and freedom within the game, are characteristics valued by the participants, regardless of whether they already have the habit of playing or not. As for the negative characteristics, or characteristics that the participants do not like in a game, for those who already have the habit of playing, cruelty, inappropriate content, or misogynist have a greater weight than other characteristics such as not being pretty, characteristic most mentioned by participants who are not in the habit of playing games.

The validation and triangulation of the data obtained in the interviews were carried out, where it was possible to validate aspects mentioned by the interviewees and by the respondents to the questionnaire and to identify characteristics mentioned by only one group. It was also possible to generate an overview of gender preferences in games, with comparisons made with male respondents to the questionnaire. A certain divergence was identified concerning violence in games. As presented in Section 2.2, some studies mention that girls prefer non-violent games and that they are clearly opposed to games that contain this kind of content. However, based on the analysis of the interviews and questionnaire, it was identified that the participants have no resistance against violence, in general, but they do not seem to like games in which there is extreme violence, cruelty, and suffering.

iSys: Revista Brasileira de Sistemas de Informação (iSys: Brazilian Journal of Information Systems) http://seer.unirio.br/index.php/isys/ 
Among the results obtained, the following suggestions for the adequacy of digital games were highlighted, which can contribute to attracting more girls to play:

- Check how the players will interact, whether using chats, video or audio calls, and other resources that allow them to have contact when they play.

- It is important to observe how the game will demonstrate reality, either with realistic graphics or with the simulation of real life.

- Design the game to be nice and beautiful.

- Provide players with some way to be classified, for example, in a ranking, and provide competition between them, enabling evolution and challenges in the game. The level of competition must be balanced so that there is no excessive competition between players.

- The game should provide mental challenges to the players, requiring the player to use reasoning and strategy.

- Enable the player to explore their creativity, have the freedom to build what they want, and choose which paths the narrative will follow.

- Provide the player with a feeling of well-being and relaxation, combined with the feeling of adrenaline rush.

- Games that have violent content should be designed in a way that does not work with cruelty, that is, the pleasure of causing suffering, as is the case with torture.

- Designing inclusive and egalitarian games, where any type of insult, sexist or prejudiced attitudes, whether in the game or in the exchange of messages, are not allowed. It is recommended that the game storyline does not favor only the male gender.

- The game should have female avatars that could be selected.

- In addition to the inclusion of female avatars in the game, it is of great relevance that these avatars are representative and inclusive, with variations in physical characteristics, portraying all ethnicities.

- Represent women in a positive way, not in a stereotyped and objectified way.

- Design female characters to play champion roles, not just supporting roles. Enable these characters to also be main characters, who have their own story, not linked to a male character.

- The game should be 'free to play', and not 'pay to win', without promoting any kind of advantage among players.

- Include in the games sentimental aspects, providing players with memories of happy moments and that stimulate their imagination.

It is worth noting that the suggestions mentioned as adequacies refer to characteristics that had at least five mentions or were reinforced at different times in the results, as is the case of Many female avatars, which was mentioned by three girls as one aspect that they value in a game, but was also a suggestion for games.

Among the contributions, the following stand out:

- The set of suggested adjustments for digital games.

- The discussion and understanding of valued features, not valued features, and features that participants would like to see in games.

iSys: Revista Brasileira de Sistemas de Informação (iSys: Brazilian Journal of Information Systems) http://seer.unirio.br/index.php/isys/ 
- Collaboration with game recommendation systems, in which the characteristics identified in this study can help to map the user profile, as well as refine the recommendation function.

Another important contribution is the Gamebook game set. The games selected were chosen according to the results of the analyses, taking into account aspects valued by the interviewees, and meeting a large number of adequacy suggestions. The games are: Forza, Injustice, League of Legends, Minecraft, Fifa, Gartic, Life is strange and The Sims.

\subsection{Limitations of research and threats to validity}

The validity of a research refers to the degree of confidence of the elements covered in its execution process, how they are presented, what is the theoretical basis and the results achieved [Travassos et al. 2002]. Thus, threats to three types of validity were evaluated: Internal, External, and Reliability.

Internal validity refers to how the results obtained relate to reality and what is its credibility. [Merriam 2009] describes that in the qualitative research approach, reality can provide multiple constructions of how individuals experienced some situation or phenomenon, and it is something that is constantly changing. In this way, the researcher is the main data collection and analysis tool, and the understanding of reality can be observed through their comments, so that reality is interpreted, not measured [Merriam 2009, Abdalla 2013]. To mitigate the threat to internal validity, different data collection instruments were used in this study, namely interviews and questionnaires. In the interviews, we sought to question the participants about the definitions of the characteristics they mentioned, to understand their point of view, and interpret the characteristics according to the understanding of the interviewees, rather than the researcher, avoiding biased interpretations in the research. The interviews were conducted at distance, due to the Covid-19 pandemic, and the observation of reactions of participants and feelings, when asked about a specific fact, may be different than when the interview is conducted in person. A validation questionnaire was used, which aimed to minimize the risks, verifying what was or was not mentioned in common with the interviewees.

External validity refers to the degree of generalization of the results achieved. [Lincoln and Guba 1985] suggest the idea of transferability in the qualitative approach, in which it is up to the reader of the study to identify whether or not it extends to its context [Abdalla 2013]. Therefore, the study needs to describe the data as detailed as possible. It is important to remember that the results achieved in this study cannot be generalized, that is, to generalize the interest or preference of some women as a portrait of a group in general. To mitigate the threat to external validity, we sought to describe in detail the selection and profile of the participants, the steps taken, and how the results were analyzed, taking into account the opinions and comments made by the participants.

Reliability refers to the ability to replicate the results, that is, whether the study will produce the same results if repeated [Merriam 2009, Abdalla 2013]. In qualitative research, reliability is somewhat complex, as the replication of qualitative research will hardly produce the same results, but it does not mean that the results are invalid [Merriam

iSys: Revista Brasileira de Sistemas de Informação (iSys: Brazilian Journal of Information Systems) http://seer.unirio.br/index.php/isys/ 
2009]. [Lincoln and Guba 1985] suggest the idea of consistency in the qualitative approach, in which the results are expected to be plausible with the data collected, and [Merriam 2009] concluded that if the results of a survey are consistent with the data and information presented, the research can be considered to be reliable. Thus, the same approach was used to mitigate the threat to external validity and reliability, detailing each activity performed and reporting and analyzing the data obtained.

\subsection{Future works}

As future works it is intended to develop quantitative studies with a larger number of participating girls, to validate the results obtained in this research, and to present results that can lead to a greater social impact. It is also possible to compare the data obtained in the interviews with female players and with male players, to contrast different and common aspects between both social groups.

\section{Acknowledgement}

This study was financed in part by the Coordenação de Aperfeiçoamento de Pessoal de Nível Superior - Brasil (CAPES) - Finance Code 001.

\section{References}

Abdalla, M. M. (2013). A estratégia de triangulação: objetivos, possibilidades, limitações e proximidades com o pragmatismo. Anais do $4^{\circ}$ Encontro de Ensino e Pesquisa em Contabilidade.

AlSulaiman, S. and Horn, M. (2015). Peter the fashionista? In Proceedings of the 2015 Annual Symposium on Computer-Human Interaction in Play, pages 185-195, Northwestern University, Chicago, IL, USA. ACM.

Ansari, R., Jaffar, B. A., Riaz, S., Kaur, M. J., and Mushtaq, A. (2019). Datamining to alert the formation of women objectification stereotypes in video games. In 2019 Amity International Conference on Artificial Intelligence (AICAI), pages 521-526, Amity University Dubai, UAE. IEEE, IEEE.

Araujo, G. and Pereira, G. (2017). Não se preocupem queridos, a cavalaria chegou: análise crítica do design das personagens de overwatch. SBC-Proceedings of XVI SBGames, pages 17-26.

Bayde, L., PR Filho, F. E., and de Araújo, G. P. (2019). Da inglaterra à runeterra: representatividade feminina nos jogos como um reflexo da sociedade, com foco em league of legends. SBC-Proceedings of XVI SBGames, pages 710-719.

Benedicta, M. K. (2021). Generation Examination: A Phenomenological Study of Generation X Women and Mobile Games. PhD thesis, Dominican University.

Bergstrom, K. (2019). Barriers to play: Accounting for non-participation in digital game play. Feminist Media Studies, 19(6):841-857.

Bristot, P. C., Pozzebon, E., and Frigo, L. B. (2017). A representatividade das mulheres nos games. SBC-Proceedings of XVI SBGames, pages 862-871.

iSys: Revista Brasileira de Sistemas de Informação (iSys: Brazilian Journal of Information Systems) http://seer.unirio.br/index.php/isys/ 
Cai, X., Cebollada, J., and Cortiñas, M. (2021). From traditional gaming to mobile gaming: Video game players' switching behaviour. Entertainment Computing, page 100445 .

Cardoso, S. P. (2019). Árida, um estudo sobre a representação feminina no jogo.

Cerdera, C. P. and Lima, M. (2016). Estereótipos de gênero em videogames: diálogos sobre sexismo, homofobia e outras formas de opressão na escola. SBC-Proceedings of XV SBGames, pages 955-961.

Cunningham, C. M. (2016). She designs therefore she is?: Evolving understandings of video game design. In Examining the Evolution of Gaming and Its Impact on Social, Cultural, and Political Perspectives, pages 147-169. IGI Global, Gonzaga University, USA.

Dale, G., Joessel, A., Bavelier, D., and Green, C. S. (2020). A new look at the cognitive neuroscience of video game play. Annals of the New York Academy of Sciences, 1464(1):192-203.

de Amorim, F. M., Leão, S. N., Liao, G. G., and Gallo, S. N. (2016). A indumentária nos jogos digitais: Incoerências nas representações femininas. SBC-Proceedings of XV SBGames, pages 272-280.

Dele-Ajayi, O., Strachan, R., Pickard, A., and Sanderson, J. (2018). Designing for all: Exploring gender diversity and engagement with digital educational games by young people. In IEEE Frontiers in Education Conference (FIE), pages 1-9, San Jose, CA, USA. IEEE.

Desai, N., Zhao, R., and Szafron, D. (2017). Effects of gender on perception and interpretation of video game character behavior and emotion. IEEE Transactions on Computational Intelligence and AI in Games, 9.

Dickey, M. D. (2006). Girl gamers: The controversy of girl games and the relevance of female-oriented game design for instructional design. British journal of educational technology, 37(5):785-793.

Flick, U. (2008). Introdução à pesquisa qualitativa. Artmed editora, Porto Alegre.

Fontoura, M. M., Rodrigues, L., Leite, P., Amaral, M. A., Almeida, L. D. A., and Merkle, L. E. (2019). Relações de gênero em mecânicas de jogos. Proceedings of SBGames, pages $794-803$.

Fordham, J., Huang, K.-T., and Corrie (2014). Girls getting played: Video game stereotype effects on gendered career perceptions. In Proceedings of 4th International Academic Conference on Meaningful Play, pages 1-8, Michigan State University, USA. MSU.

Fortim, I., de França Monteiro, L., Sancassani, V., and Bengel, M. J. (2016). A tipologia das jogadoras: Um estudo do público feminino gamer brasileiro. In $S B C$-Proceedings of XV SBGames, volume 3, pages 1312-1319, São Paulo. SBC.

Gao, G., Min, A., and Shih, P. (2017). Gendered design bias: Gender differences of in-game character choice and playing style in league of legends. In $\mathrm{OZCHI}$ '17: Pro-

iSys: Revista Brasileira de Sistemas de Informação (iSys: Brazilian Journal of Information Systems) http://seer.unirio.br/index.php/isys/ 
ceedings of the 29th Australian Conference on Computer-Human Interaction, pages 307-317, Brisbane Queensland, Australia. ACM.

Guest, G., Bunce, A., and Johnson, L. (2006). How many interviews are enough? an experiment with data saturation and variability. Field methods, 18(1):59-82.

Harrison, R. L., Drenten, J., and Pendarvis, N. (2016). Gamer girls: navigating a subculture of gender inequality. In Consumer Culture Theory, pages 47-64. Emerald Group Publishing Limited, Loyola University Chicago, USA.

Hartmann, T. and Klimmt, C. (2017). Gender and computer games: Exploring females' dislikes. Journal of Computer-Mediated Communication, 11(4):910-931.

Hosein, A. (2018). Girls' video gaming behaviour and undergraduate degree selection: A secondary data analysis approach. Computers in Human Behavior, 91:226-235.

Huang, V., Young, M., and Fiocco, A. J. (2017). The association between video game play and cognitive function: does gaming platform matter? Cyberpsychology, Behavior, and Social Networking, 20(11):689-694.

Jenkins, H. (1998). Voices from the combat zone: Game grrlz talk back. In From Barbie to Mortal Kombat: gender and computer games, pages 328-341. MIT Press, Cambridge, MA, USA.

Jenkins, H. and Cassell, J. (2008). From quake grrls to desperate housewives: A decade of gender and computer games. Beyond Barbie and Mortal Kombat: New perspectives on gender and gaming, pages 5-20.

Kafai, Y. B. and Burke, Q. (2014). Beyond game design for broadening participation: Building new clubhouses of computing for girls. In Proceedings of Gender and IT Appropriation. Science and Practice on Dialogue - Forum for Interdisciplinary Exchange, pages 21-28, Artur-Woll-Haus, Am Eichenhang 50, DEU. European Society for Socially Embedded Technologies.

Kaufman, G., Flanagan, M., and Freedman, G. (2019). Not just for girls: Encouraging cross-gender role play and reducing gender stereotypes with a strategy game. In $\mathrm{CHI}$ PLAY '19: The Annual Symposium on Computer-Human Interaction in Play, pages 481-493, Barcelona, Spain. ACM.

Kelle, U. (2001). Sociological explanations between micro and macro and the integration of qualitative and quantitative methods, forum qualitative. In Social Research, volume 2, pages 1-22, Hamburg, Germany. Citeseer, Citeseer.

Kurtz, G. B. (2017). Manifestações de violência simbólica contra a mulher nos videogames: uma revisão bibliográfica. Metamorfose, 2(1):91-109.

Laato, S., Islam, A. N., and Laine, T. H. (2020). Did location-based games motivate players to socialize during covid-19? Telematics and Informatics, 54:101458.

Lantz, C. E. (2015). Women, Gaming and STEM Majors: Interest and Motivation. PhD thesis, University of Southern California.

Lima, C. R. H. et al. (2019). Level up: mulheres em combate: uma análise sobre a participação feminina na indústria dos games.

iSys: Revista Brasileira de Sistemas de Informação (iSys: Brazilian Journal of Information Systems) http://seer.unirio.br/index.php/isys/ 
Lin, H. (2008). Body, space and gendered gaming experiences: a cultural geography of homes, cybercafes and dormitories. Beyond Barbie \& Mortal Kombat: New perspectives on gender and gaming, pages 67-82.

Lin, S.-Y., Chien, S.-Y., Hsiao, C.-L., Hsia, C.-H., and Chao, K.-M. (2020). Enhancing computational thinking capability of preschool children by game-based smart toys. Electronic Commerce Research and Applications, 44:101011.

Lincoln, Y. and Guba, Y. (1985). Naturalistic inquiry.

Martins, A., Silva, J., Santos, J., and Rebouças, A. (2019). Fatores que atraem e afastam as meninas de cursos da área de ti. In Anais do XIII Women in Information Technology, pages 114-118, Porto Alegre. SBC.

Martín-Sómer, M., Moreira, J., and Casado, C. (2021). Use of kahoot! to keep students' motivation during online classes in the lockdown period caused by covid 19. Education for Chemical Engineers, 36:154-159.

Merriam, S. B. (2009). Qualitative case study research. Qualitative research: A guide to design and implementation, pages 39-54. Disponível em: ¡https://bit.ly/3noQGW2i. Acesso em: 15 dez. 2020.

Ochsner, A. (2015). Lessons learned with girls, games, and design. In GenderIT '15: The Third Conference on GenderIT, pages 24-31, Philadelphia PA, USA. ACM.

Olsson, M. (2018). "true gamer" culture on twitch and its effect on female streamers. Disponível em: ¡https://5dok.org/document/rz3g3m7y-quot-true-gamer-culturetwitch-effect-female-streamers.htmli. Acesso em: 21 out. 2019.

Papalia, D., Olds, S., and Feldman, R. (2006). Desenvolvimento humano. Disponível em: ¡https://bit.ly/3gMe8Kri . Acesso em: 14 out. 2019.

Ribeiro, G. C. B. (2019). O sexismo nos jogos eletrônicos: Barreiras à participação feminina em league of legends.

Rogers, V. L. N. (2015). Women in it: the endangered gender. In Proceedings of the 2015 ACM SIGUCCS Annual Conference, pages 95-98, University of Georgia, USA. ACM.

Rosa, K. S., Ferreira, M. N. B., and Nesteriuk, S. (2018). A jornada da heroína: outra abordagem da representação feminina nos games. In $S B C$-Proceedings of XVII SBGames, pages 240-243, Foz do Iguaçu - PR. SBC.

Saláfia, J. S., Ferreira, N. B., and Nesteriuk, S. (2018). Os estereótipos em jogos de luta: da indumentária à hipersexualização de personagens femininas. SBC-Proceedings of XVII SBGames, pages 225-232.

SBC (2019). Educação superior em computação estatısticas - 2019. Disponível em: ihttps://www.sbc.org.br/documentos-da-sbc/send/133-estatisticas/1354-educacaosuperior-em-computacao-estatisticas-2019i. Acesso em: 03 jul. 2021.

Schmidt, A. F., de Carvalho Gusso, L., and Carelli, M. N. (2021). As mutações dos jogos digitais e analógicos nos últimos 50 anos: Fliperamas, lan houses, luderias e a pandemia do covid19. TROPOS: COMUNICAÇÃO, SOCIEDADE E CULTURA (ISSN: 2358-212X), 10(1).

iSys: Revista Brasileira de Sistemas de Informação (iSys: Brazilian Journal of Information Systems) http://seer.unirio.br/index.php/isys/ 
Schultheiss, D. (2017). "from the weaker sex to hardcore gaming": Female gaming patterns on the internet. Computers in Entertainment, 15:1-8.

Shaer, O., Westendorf, L., Knouf, N., and Pederson, C. (2017). Understanding gaming perceptions and experiences in a women's college community. In CHI '17: CHI Conference on Human Factors in Computing Systems, pages 1544-1557, Denver Colorado, USA. ACM.

Travassos, G. H., Gurov, D., and do Amaral, E. A. G. (2002). Introdução à engenharia de software experimental. Disponível em: ¡encurtador.com.br/bkvPZ $i$. Acesso em: 15 dez. 2020.

Vanderhoef, J. (2013). Casual threats: The feminization of casual video games. Ada: A Journal of Gender, New Media, and Technology, 2(2013).

Veltri, N., Krasnova, H., Baumann, A., and Kalayamthanam, N. (2014). Gender differences in online gaming: a literature review. In Proceedings of 20th Americas Conference on Information Systems, Savannah, Georgia, USA. AMCIS.

Vergara, S. C. (2006). Métodos de pesquisa em administração. Disponível em: ¡https://bit.ly/386auXA $i$. Acesso em: 10 jul. 2019.

Vermeulen, L., Castellar, E. N., Janssen, D., Calvi, L., and Van Looy, J. (2016). Playing under threat. examining stereotype threat in female game players. Computers in Human Behavior, 57:377-387.

Vieira, P. P. and da Mota, R. R. (2018). A representação feminina em horizon zero dawn. In SBC-Proceedings of XVII SBGames, pages 694-703, Foz do Iguaçu - PR. SBC.

Vinuto, J. (2014). A amostragem em bola de neve na pesquisa qualitativa: um debate em aberto. Temáticas, 22(44):203-220.

Wasserman, J. and Rittenour, C. (2018). Who wants to play? cueing perceived sex-based stereotypes of games. Computers in Human Behavior, 91.

Woods, O. (2021). Feminist geographies of online gaming. Digital Geography and Society, 2:100015.

Zelinski, E. M. and Reyes, R. (2009). Cognitive benefits of computer games for older adults. Gerontechnology: international journal on the fundamental aspects of technology to serve the ageing society, 8(4):220-235.

Zhao, W. and Shute, V. J. (2019). Can playing a video game foster computational thinking skills? Computers Education, 141:103633.

\section{A. Interview script - Initial Identification of Characteristics}

- What games do you like to play?

- About game X, what does this game have that makes you like it?

- What games do you not like to play?

- About game X, what does this game have that makes you dislike it?

- Are there any features that you would like to see in games that you have not yet noticed in the games you are used to playing?

iSys: Revista Brasileira de Sistemas de Informação (iSys: Brazilian Journal of Information Systems) http://seer.unirio.br/index.php/isys/ 
For girls who are in the technology field, the following question was added:

- Do you think that the fact of playing games influenced your choice of a computing course?

For girls who are not in the CS area, the following questions were added:

- Have you had any contact with the computing area, in addition to your contact with digital games?

- Have you ever been interested in following the computing area in any way?

- If so, do you think the fact of playing has aroused this possible interest? Why?

- Are you interested in knowing more about any area related to computing?

\section{B. Interview script - Gamebook Presentation}

- Have you been interested in any game presented? If so, which games?

- About the game X, what aroused your interest in the game?

- What games are you not interested in knowing more or playing?

- What made you dislike the game?

- What features do you find interesting and suggest having in a game?

\section{Questionnaire - Validation of analyzes}

- What games do you like to play?

- What do these games have that makes you like them?

- What games do you not like to play?

- What are these games about that makes you dislike them?

- Are there any features that you would like to see in games that you have not yet noticed in the games you are used to playing?

- Do you think that the fact of playing influences the choice for a course in the technology area?

iSys: Revista Brasileira de Sistemas de Informação (iSys: Brazilian Journal of Information Systems) 